\title{
A Comparison of Energy Consumption in Bulk Forming, Subtractive, and Additive Processes: Review and Case Study
}

\author{
Hae-Sung Yoon 1,2, Jang-Yeob Lee, ${ }^{1,2}$ Hyung-Soo Kim', Min-Soo Kim', Eun-Seob Kim', Yong-Jun Shin', \\ Won-Shik Chu', and Sung-Hoon Ahn ${ }^{1,3,4,4}$ \\ 1 Department of Mechanical and Aerospace Engineering, Seoul National University, Gwanak-ro 1, Gwanak-gu, Seoul, South Korea, $151-744$ \\ 2 Lawrence Berkeley National Laboratory, 1 Cyclotron Road, Berkeley, CA, USA, 94720 \\ 3 Institute of Advanced Machinery and Design, Seoul National University, Gwanak-ro 1, Gwanak-gu, Seoul, South Korea, 151-744 \\ 4 Department of Mechanical Engineering, University of Washington, Stevens Way, Box 352600, Seattle, WA, USA, 98195 \\ \# Corresponding Author / E-mail: ahnsh@snu.ac.kr, TEL: +82-2-880-7110, FAX: +82-2-888-9073
}

KEYWORDS: Electricity consumption, Green manufacturing, Manufacturing initiatives, Manufacturing processes, Specific energy consumption (SEC), Sustainability

\begin{abstract}
In addition to the steps taken to ensure optimal efficiency in industry, significant effort has been directed towards the green and sustainable manufacturing practices. In this paper, we review conventional and state-of-the-art manufacturing technologies to provide insight into energy consumption at the processing level. In the review, collected energy data were summarized for three manufacturing categories: conventional bulk-forming, subtractive, and additive manufacturing (AM) processes. Additive processes, in particular, are strongly emphasized in the Advanced Manufacturing Initiatives proposed recently by the United States government. Currently, the specific energy consumption (SEC) of additive processes is estimated to be $\sim 100-$ fold higher than that of conventional bulk-forming processes, with subtractive processes showing intermediate values that varied over a wide range in terms of scale. Although SEC may vary with respect to the details, in general, the research showed a negative correlation with respect to the reciprocal logarithmic form of the productivity. In addition to the literature review presented, we performed case studies for the three manufacturing processes, to provide practical examples of energy consumption. Additionally, our results indicated that AM processes may require more extensive evaluation; i.e., an assessment of the entire manufacturing cycle, for more accurate prediction of the subsequent environmental impact.
\end{abstract}

Manuscript received: May 5, 2014 / Revised: May 23, 2014 / Accepted: May 26, 2014

\section{Introduction}

Over the last few decades, sustainability has emerged as a buzzword in almost every field. Depletion of conventional fossil fuels is forecast to cause a serious imbalance in energy supply and demand, and emerging carbon emission is expected to lead to critical greenhouse effects. Skyrocketing population growth is expected accelerate this trend in overall energy use. Research by the United States (U.S.) Energy Information Administration indicates that the increasing trend in world energy consumption will continue over the next several decades, as shown in Fig. 1; in fact, among various sectors in the U.S., manufacturing/industry is responsible for a large portion of the overall energy consumption $(\sim 31 \%)$, as shown in Fig. 2 Worldwide, the industrial sector accounts for $\sim 37 \%$ of the energy consumption and
$17 \%$ of the carbon dioxide emissions. ${ }^{2}$

Considerable effort has been directed towards reducing the overall energy consumption and carbon emission, particularly in industry. This recent shift to more environmentally responsible manufacturing practices ${ }^{4}$ has prompted new environmental legislation initiatives, mainly in European countries. The European Association of the Machine Tool Industries (Comité Européen de Coopération des Industries de la Machine-Outil (CECIMO)) proposed a self-regulatory initiative in 2009. ${ }^{5}$ The European Commission announced the Energy Efficiency Directive 2012/27/EU in 2012, through the ECODESIGN Directive 2009/125/EC and Energy Labelling Directive 2010/30/EU. ${ }^{6}$

Table 1 shows several International Organization for Standardization (ISO) environmental regulation standards, either already published or currently under development. Numerous attempts have been made to 


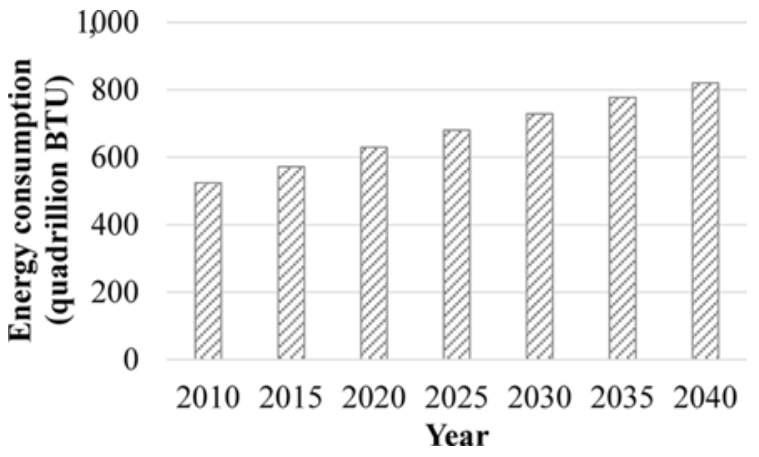

Fig. 1 World energy consumption and projection (redrawn using data from U.S. Energy Information Administration ${ }^{1}$ )

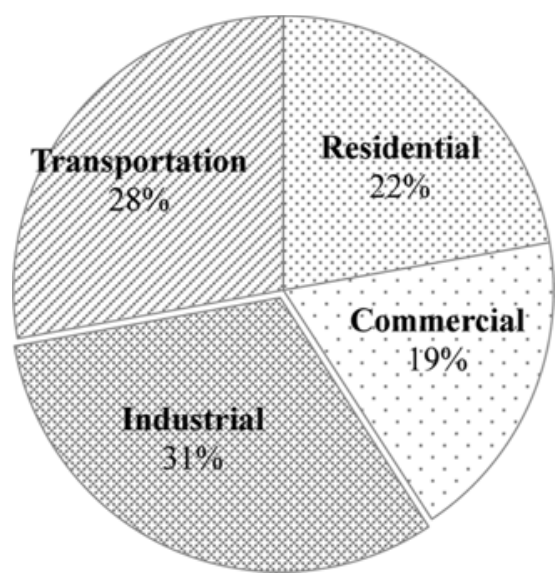

Fig. 2 Energy consumption by sector in the United States (redrawn using data from U.S. Energy Information Administration ${ }^{3}$ )

Table 1 International Organization for Standardization (ISO) standards related to environmental factors ${ }^{10}$

\begin{tabular}{cc}
\hline ISO standards & Title \\
\hline ISO/DIS 14955 & $\begin{array}{c}\text { Machine tools - Environmental evaluation of } \\
\text { machine tools }\end{array}$ \\
\hline ISO/DIS 20140 & $\begin{array}{c}\text { Automation systems and integration -Evaluating } \\
\text { energy efficiency and other factors of } \\
\text { manufacturing systems that influence the } \\
\text { environment }\end{array}$ \\
\hline ISO/DIS 50001 & $\begin{array}{c}\text { Energy management systems - Requirements with } \\
\text { guidance for use }\end{array}$ \\
\hline
\end{tabular}

standardize environmental performance in an effort to provide meaningful eco-directives for industry. Additionally, cooperative research efforts, such as the Eco-machine Tools project ${ }^{7}$ and the Cooperative Effort on Process Emissions in Manufacturing (CO2PE!), ${ }^{8}$ have analyzed the environmental footprint of various manufacturing processes, to improve efficiency and reduce greenhouse gas emissions.

Metal-working machine tools are commonly used in the industrial sectors. The Japanese Standards Association (JSA) published the TS B0024 standards (Test Methods for Electric Power Consumption) ${ }^{9}$ to measure the power consumption of machine tools; this prompted the development of efficient, environmentally friendly machine tools (e.g., the Eco series (DMG Mori) and the Genos series (OKUMA)).

Green and sustainable manufacturing is increasingly gaining a foothold in mainstream research and industry. However, although numerous studies have investigated the monitoring of energy consumption in manufacturing lines, standards for energy measurement, and the means to implement energy-saving strategies based on these measurements, have yet to be developed. The difficulty lies in comparing different manufacturing processes. The specific energy demands of individual processes in the manufacturing cycle may require different types of energy source and material; thus, it is difficult to precisely quantify the economic aspects. ${ }^{11}$ Moreover, novel manufacturing techniques (e.g., additive manufacturing techniques) continue to be developed.

Therefore, the present review provides an overview of three manufacturing processes: bulk-forming, subtractive, and additive processes, and compares these processes for effective energy modeling and production planning. Data from published research were collected to create a model for each process. The current energy characteristics and expected future flow of each process were compared with experimental results from several case studies.

Because monitoring and modeling of energy consumption is important for energy savings, a review of the actual energy consumption in unit production will provide useful insight to users for selection of the appropriate manufacturing process. Effective modeling and process planning will facilitate standardization of green manufacturing practices. Additionally, the development of novel manufacturing techniques will be able to provide various alternatives for product manufacture, based on environmental factors and energy consumption predictions.

\section{Research Objectives}

The main focus of this review is the energy consumption and modeling of manufacturing processes. For comparison, conventional bulk-forming and subtractive processes (i.e., injection molding, metal casting, and conventional machining processes) were considered. Bulk 'forming' and 'subtraction' of material are very basic, traditional concepts in three-dimensional (3-D) manufacturing, and thus, have been widely adopted over the years.

In addition to bulk-forming and subtractive processes, additive manufacturing ( $\mathrm{AM}$ ) processes were also included in this review. AM, generally referred to as 3-D printing, forms an object by layer-by-layer deposition of materials, based on 3-D computer-aided design (CAD) specifications. Although AM was developed and commercialized in the 1980s, recent manufacturing initiatives by the current U.S. administration have increased interest in this technology.

In 2013, the Obama administration launched a competition to build three federally funded manufacturing innovation institutes in the U.S.: ${ }^{12}$ 'Digital Manufacturing and Design Innovation,' 'Lightweight and Modern Metals Manufacturing,' and 'Next Generation Power Electronics Manufacturing.' Following the government's initiative, the National Network for Manufacturing Innovation (NNMI) was created to connect manufacturing industries, universities, and local colleges. ${ }^{13}$

Following the initiatives, AM was re-focused as a future manufacturing technology, due to its shortened lead time, ability in mass customization, and lower lifecycle energy. In 2012, the National Additive Manufacturing Innovation Institute (NAMII) was introduced, with a federal commitment of 30 million U.S. dollars (USD). ${ }^{14}$ 


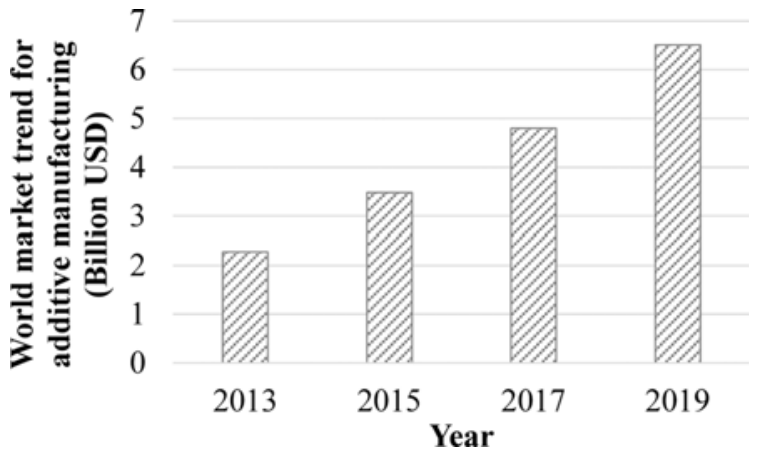

Fig. 3 World market trend of additive manufacturing (AM) products, material and services (redrawn using data from Atmel, original source from Credit Suisse estimates) ${ }^{16}$

Based on these programs and the strong support from the U.S. government, AM products and the associated service market are expected to grow rapidly, as shown in Fig. $3 .^{15} \mathrm{AM}$ applications continue to spread, from traditional aerospace and dental technologies to automotive, academic, and architectural fields. Hence, in this review, energy consumption in stateof-the-art AM processes was evaluated, in addition to conventional manufacturing technologies (i.e., bulk-forming and subtractive processes).

As described in the previous chapter, the importance of energy efficiency in manufacturing practices was further highlighted by President Obama's executive order for investment in industrial energy efficiency. ${ }^{17}$ However, a comparison of the precise sustainability of different manufacturing processes can be difficult; for example, process energy consumption can differ in terms of monitoring level and assessment cycle. Detailed product design and process parameters are required to determine the suitability of energy consumption models. Nevertheless, from the perspective of a process manager, it is important to have insight into the environmental and energy aspects of various manufacturing processes.

Therefore, in this study, experimental results from various manufacturing processes were reviewed. The energy consumption of each process was calculated in terms of specific energy consumption (SEC), and then compared with the performance of other processes. Although values may vary with local conditions, this study provides an overview of the energy consumption range for the given process. The construction of the energy model depends on the manufacturing process. Modeling and energy predictions should consider the individual components/processes or process states in the manufacturing cycle.

Finally, we performed several case studies representing the three manufacturing processes (i.e., bulk-forming, subtractive, and additive), for fabrication of a 3-D test-sample part. Empirical and experimental results were compared. From the case study results and the results from the literature, an energy consumption model was developed to facilitate estimation of the overall energy consumption of the process. Our results showed that based on minimum energy criteria, the energy consumption for forming an object can be predicted at the macro-scale, allowing selection of the appropriate green manufacturing process for product development.

\section{Scope}

Many research groups have investigated various frameworks for energy-consumption monitoring. Vijayaraghavan and Dornfeld ${ }^{18}$

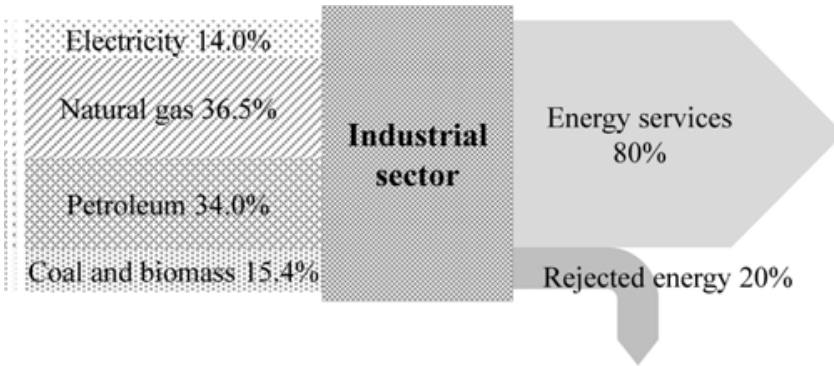

Fig. 4 Energy flow diagram of the U.S. industrial sector (reproduced using data from U.S. Department of Energy) ${ }^{21}$

divided the analysis of the manufacturing level into activity and temporal decision scales. Wang et al. $^{19}$ analyzed the energy consumption of a process with respect to individual processing layers, as well as the overall manufacturing process. Duflou et al. suggested five levels of energy-saving strategies, ranging from individual device/ unit processes to an enterprise/global supply chain. ${ }^{20}$

Because energy-consumption characteristics or the effect of process parameters vary with respect to the energy monitoring level, the minimum energy-consumption point may also vary in terms of this level. For the case of AM processes in particular, energy reduction of the entire lifecycle of the product provides substantial environmental insight. However in the present review, only the energy consumption at the processing level of the manufacturing phase was considered.

On the other hand, collecting accurate input data for different levels of manufacturing cost and different energy models can be difficult. ${ }^{11}$ Because the research objective was to provide a practical energy consumption model and experimental values for various manufacturing processes, only directly measured values corresponding to specific machines and specific part production were considered.

For the environmental aspects, electricity consumption during the manufacturing process was the main consideration. In fact, various types of energy source were consumed during the manufacturing processes considered. Fig. 4 shows the energy flow for the U.S. for various energy sources and the utilization rate in the industrial sector. A total of 23.9 quadrillion BTUs of energy are consumed in the U.S. industrial sector, with $\sim 70 \%$ of the total energy consumption being in the form of natural gas and petroleum. ${ }^{21}$

Although gas and petroleum are major energy sources, their consumption and efficiency depend on the specific manufacturing process. Electricity is a major energy source in certain types of manufacturing processes, ${ }^{22}$ and may be a secondary source of energy from other types of fuel. Due to the simplicity of the representation, electricity consumption at the end-use phase of a single process level was considered in this study to evaluate the environmental effects of various manufacturing processes.

Note that the rejected rate of electricity generation and utilization is higher than utilization of a primary energy source directly ${ }^{21}$ hence, the form of energy consumption at the end-use was considered in this study. Also, when the process involved the use of fuel, an exception was considered when electricity was not used as the main energy source.

Considering these points, several manufacturing processes were selected and categorized into one of the three processes: conventional bulk-forming, subtractive, and additive processes. For each category, 
market-representative manufacturing techniques were considered: injection molding and metal-casting for conventional bulk-forming processes, conventional mechanical machining for subtractive processes, and fused deposition modeling (FDM), selective laser sintering (SLS), and stereolithography for additive processes. In this review, the energy consumption of the three different categories of manufacturing processes was evaluated for individual processing levels. Despite some exceptions, electricity consumption was considered to be the main energy source and provided an approximate comparison of the energy consumption involved in the manufacturing processes.

\section{Specific Energy Consumption (SEC) of Manufacturing Processes}

Fig. 5 shows a schematic diagram of the three manufacturing categories (bulk-forming, subtractive, and additive processes). Conventional bulk-forming processes involve activities that form a bulk 3-D structure, mainly from its molten state. To acquire the desired shape, a die is usually used; the molten material is then injected into or founded in the die.

In contrast, a subtractive process removes a certain volume of material, usually with a cutting edge. Before material removal, a bulk form of the material is prepared. The embodied energy of the material has an impact on the material removal energy. Additive processes, as described earlier, form a structure by powdered or molten material deposition (e.g., laser sintering). Compared with the two former types of process, a relatively small amount of material is deposited onto a substrate, and the structure forms from the bottom up.

For energy consumption calculations, only the main processes were considered for the three categories described. Fabrication of a mold cavity is usually essential for all types of conventional bulk-forming processes, as shown in Fig. 5(a). However, given that the research objective was to provide an energy-consumption range for the process, only the power consumed in injection and ejection of the material was considered. In contrast, for the additive processes, several essential post-processes were considered as main processes, because they were performed immediately following deposition as part of the main process.

The concept of SEC was used to facilitate comparisons among manufacturing processes. SEC is defined as the energy consumed in the production of a material unit. The material unit depends on the process characteristics. For subtractive processes, in the literature, many studies defined SEC as 1 joule per unit volume of material. For the case of additive processes, SEC is defined as 1 joule per unit mass of material, because the material density is affected by the processing parameters. Though material preparation can account a significant portion among the total, only the SEC consumed in main process was considered as mentioned.

In this chapter, the SECs of individual processes were considered, and then compared in each category with comparable sets. For the calculation of energy consumption, preparation and idle energy were included; however, pre- or post-processes (e.g., mold making), were not. Again, the purpose was to provide insight into the individual

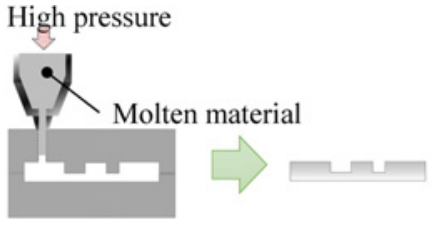

Mold fabrication Injection molding Ejection from mold

(a) Conventional bulk forming process

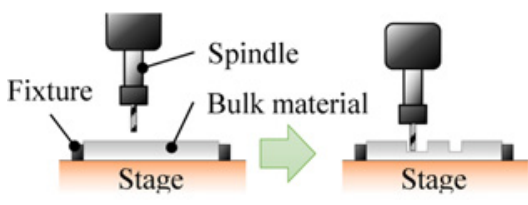

Setup for machining

Machining

Remove from fixture

(b) Subtractive process

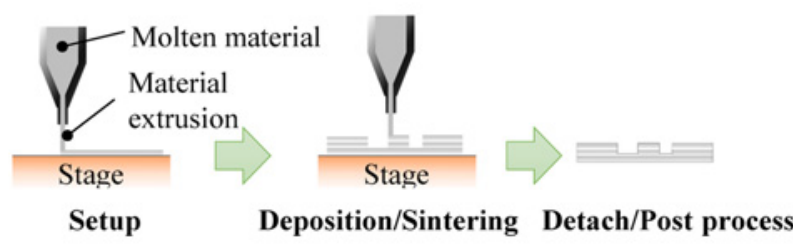

(c) Additive process

Fig. 5 Schematic diagram of the three manufacturing processes considered in this study; only the main processes were considered

targeted processes. An integrated comparison of different categories and overall energy consumption is provided in the Discussion section.

\subsection{Conventional Bulk-forming Processes}

The term 'manufacturing' involves all activities involved in transforming raw material into a desired product. Among various manufacturing activities, the term 'forming', one of the oldest manufacturing methods, refers to the process by which a material is transformed into the desired shape. From this perspective, various types of bulk deformation can be included in bulk-forming processes.

However, in the present research, the term 'bulk-forming' is used to refer to processes used to produce a 3-D shape by solidification of molten material; this allowed energy consumption comparison with additive processes, also used to form 3-D structures. Hence, conventional plastic-forming and metal-casting processes were the main focus.

Although there have been numerous investigations of innovative manufacturing techniques, bulk-forming processes are used by a significant portion of the industrial sector. From an energy perspective, bulk-forming processes consume large amounts of energy in the melting of material. However, they have economics with mass production, and a huge amount of products have been manufactured by bulk-forming processes. According to the U.S. Department of Energy, melting occupies the largest portion of metal-casting energy cost, over $50 \%$ of the total. ${ }^{23}$ As a result, legislation has been introduced to promote energy-efficient green practices in the plastic and metalforming industries; additionally, efforts have been made to optimize furnace and heating-coil design to improve efficiency. ${ }^{24}$

Table 2 shows the list of conventional bulk-forming methods 
Table 2 List of conventional bulk-forming methods

\begin{tabular}{ll}
\hline \multirow{3}{*}{ Plastic methods } & Injection molding \\
\cline { 2 - 2 } & \multicolumn{1}{c}{ Compression molding } \\
\cline { 2 - 2 } Metal methods & Thermoforming \\
\cline { 2 - 2 } & Die casting \\
\cline { 2 - 2 } & Sand casting \\
\cline { 2 - 2 } & Investment casting \\
\hline
\end{tabular}

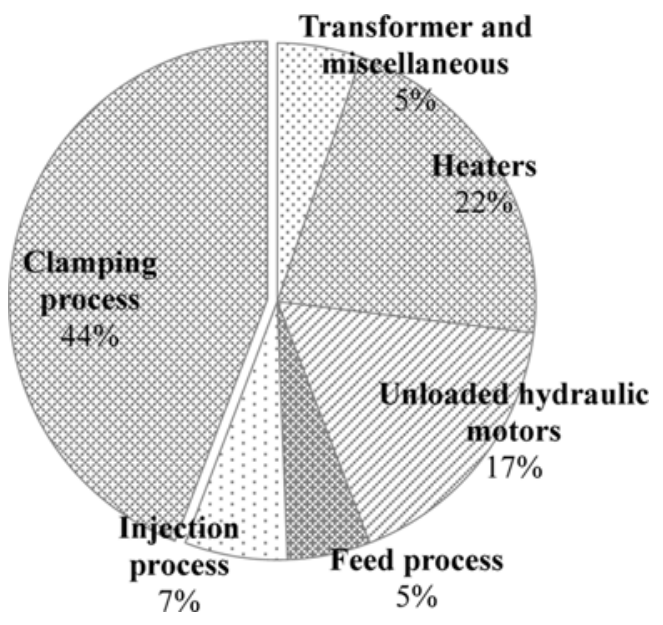

Fig. 6 Power distribution of the injection-molding process (reproduced using the data from Kordonowy $)^{27}$

considered in the present research. Among the various types of conventional bulk-forming method, we focused on injection molding and metal-casting, due to their widespread use in industry.

For injection molding of a plastic material, a certain volume of molten material is injected into a die chamber. The flow of molten material is affected by the mold geometry, and the fabricated part must be ejected from the mold. Many studies have evaluated the injectionmolding process, based on guidelines provided by the Design for Manufacturability (DFM). ${ }^{25}$

According to the Sustainable Energy Authority of Ireland (SEAI), injection molding is used in over $60 \%$ of the plastic industry. ${ }^{26}$ The SEAI claimed that European plastic-forming industries have a SEC value of $\sim 3.1 \mathrm{kWh} \mathrm{kg}^{-1}$, with specific SEC values depending on the country and the machine type used.

The energy consumption of injection-molding machines has been investigated extensively and is well-established in the literature. Kordonowy analyzed the power consumption of an injection-molding machine having a maximum pressure of 30 tons; ${ }^{27}$ here, the clamping process and heater consumed $\sim 44$ and $22 \%$ of the total consumption, respectively (Fig. 6). Note that the power of the heaters in the start-up state was used in the calculation; the power associated with the clamping process power varied according to the process.

Thiriez analyzed various types of injection-molding process with respect to the specific material, throughput rate, cycle time, and part shape used; ${ }^{28}$ the overall plastic-forming lifecycle was investigated. SEC was determined as a function of throughput $\left(\mathrm{kg} \mathrm{h}^{-1}\right)$, material, and machine type. In this research, data were acquired by assuming a polymer density of $\sim 1 \mathrm{~g} \mathrm{~mm}^{-3}$.

Mattis et al. modeled the injection-molding process by separating individual energy-consumption contributions: ${ }^{29}$
$E_{\text {INJECTION }}=E_{M E L T}+E_{F I L L}+E_{P A C K}+E_{C L A M P}+E_{E J E C T}$

where $E_{M E L T}$ is the energy consumed in melting the material, $E_{F I L L}$ is the energy consumed in pushing the material into the mold, $E_{P A C K}$ and $E_{C L A M P}$ are the energies consumed in packing and clamping the mold, respectively, and $E_{E J E C T}$ is the energy consumed in ejecting the part from the mold. Chien and Dornfeld used a similar model, based on the thermo-mechanical properties of different polymers. ${ }^{30}$ Note that the energy distribution may differ with respect to the machine type and materials used; additionally, the energy consumed in melting the material exhibited a significant dependence on the material properties.

The total energy consumed during the injection-molding process includes the energy consumed in mold making, as given below:

$$
E_{\text {TOTAL }}=E_{\text {MOLD }}+E_{\text {INJECTION }}
$$

where $E_{M O L D}$ is the energy consumed in mold making, and $E_{I N J E C T I O N}$ is the energy consumed in fabrication of the part by injection molding (Eq. 1).

$E_{\text {INJECTION }}$ increases as the number of parts increases; however, the specific energy consumed per part decreases as the number of parts increases. $E_{M O L D}$ may be considerably greater than $E_{\text {INJECTION }}$ when the number of parts is not large, because mold making may take tens of hours with respect to the complexity of the part geometry. ${ }^{31}$

Casting is one of the oldest and most popular manufacturing techniques for metal forming. In this process, a specific amount of molten metal is poured into the mold cavity, and is then ejected from the mold after solidification of the material. Casting can be divided into several detailed processes, which depend on the mold type.

For the case of metal-forming processes, energy consumption was evaluated with respect to a primary source and secondary sources. The primary energy source (e.g., fuel and gas usage) is used mainly for melting the material and is characterized by high energy intensities, compared with subtractive or additive processes.

Chougule and Ravi analyzed the cost structure of the metal-casting process, and also divided the energy into two categories: melting and others. The 'other' energy components included the energy consumed in mold-making, core-making, cleaning, and fettling, as described below: ${ }^{32}$

$$
E_{\text {TOTAL }}=E_{\text {MELT }}+E_{M O L D / C O R E}+E_{\text {CLEANING }}+E_{\text {FETTLING }}
$$

where $E_{M E L T}$ is the energy consumed in melting the material, $E_{M O L D}$ CORE is the energy consumed in making the mold and core, $E_{\text {CLEANING }}$ is the energy consumed in cleaning, and $E_{\text {FETTLING }}$ is the energy consumed in fettling the part from the mold. The basic structure of the equation is similar to that for injection molding; however, in the casting process, the injection and clamping energy are not included.

Arasu and Jeffrey analyzed energy consumption in the metal-casting process, and revealed that melting accounted for $\sim 70 \%$ of the total energy consumed. ${ }^{33}$ In their analysis of energy consumption of various casting companies with respect to electrical components, capacity utilization, annual production, and melting accounted for $75-85 \%$ of the total energy consumption, and SEC decreased as the utilization rate 
Table 3 Specific energy consumption (SEC) for various bulk-forming processes

\begin{tabular}{|c|c|c|c|}
\hline Process & $\begin{array}{r}\text { Specific energ } \\
(\mathrm{kWh}\end{array}$ & $\begin{array}{l}\text { consumption } \\
\left.\mathrm{g}^{-1}\right)\end{array}$ & Reference \\
\hline \multirow{11}{*}{$\begin{array}{l}\text { Injection } \\
\text { molding }\end{array}$} & \multirow{7}{*}{$\begin{array}{l}\text { Hydraulic } \\
\text { method }\end{array}$} & 1.47 & Duflou et al. ${ }^{34}$ \\
\hline & & $0.64-5.82$ & Thiriez $^{28}$ \\
\hline & & 3.63 & Thiriez $^{35}$ \\
\hline & & $0.48-0.94$ & Gutowski et al. ${ }^{36}$ \\
\hline & & 0.19 & Mattis et al. ${ }^{29}$ \\
\hline & & $0.28-1.94$ & Krishnan et al. ${ }^{37}$ \\
\hline & & $0.65-2.53$ & Chien and Dornfeld ${ }^{30}$ \\
\hline & Hybrid method & $0.47-2.04$ & Thiriez $^{28,35}$ \\
\hline & \multirow{3}{*}{$\begin{array}{l}\text { Electric } \\
\text { method }\end{array}$} & $0.11-0.37$ & Kanungo and Swan ${ }^{38}$ \\
\hline & & 1.86 & Thiriez $^{35}$ \\
\hline & & $0.33-1.27$ & Thiriez $^{28}$ \\
\hline \multirow{11}{*}{ Metal casting } & \multicolumn{2}{|c|}{4.44 (Aluminum) } & Sutherland et al. ${ }^{39}$ \\
\hline & \multicolumn{2}{|c|}{7.78 (Cast iron) } & Boustead and \\
\hline & \multicolumn{2}{|c|}{4.72 (Steel) } & Hancock $^{40}$ \\
\hline & \multicolumn{2}{|c|}{0.62 (Iron)+ } & Arasu and Jeffrey ${ }^{33}$ \\
\hline & \multicolumn{2}{|c|}{$3.12-4.63+$} & Jones $^{41}$ \\
\hline & \multicolumn{2}{|c|}{$2.69+$} & Dalquist and Gutowski ${ }^{42}$ \\
\hline & \multicolumn{2}{|c|}{1.69 (EAF, 2003)* } & \\
\hline & \multicolumn{2}{|c|}{6.31 (BF-BOF, 2003)* } & \\
\hline & \multicolumn{2}{|c|}{2.02 (EAF, 2006)* } & Hasanbeigi et al. ${ }^{43,44}$ \\
\hline & \multicolumn{2}{|c|}{6.89 (BF-BOF, 2006)* } & \\
\hline & \multicolumn{2}{|c|}{4.13 (Overall) } & \\
\hline
\end{tabular}

+ Foundry company average

* Industry average

EAF: Electric arc furnace

BF-BOF: Blast furnace-Basic oxygen furnace

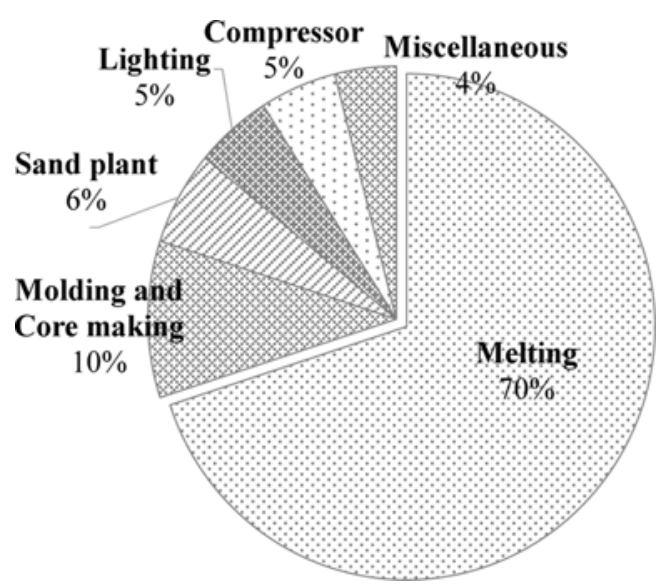

Fig. 7 Energy distribution of the casting process (reproduced using data from Arasu and Jeffrey $)^{33}$

increased. Fig. 7 shows the detailed energy distribution of the overall casting process. Unlike Fig. 6, for the case of injection molding, no energy was consumed in clamping the mold or hydraulic injection. Table 3 shows the calculated SECs of injection-molding and metalcasting processes from the literature.

Fig. 8 shows the SEC for conventional bulk-forming processes, and Fig. 9 shows the trend of SEC, in terms of throughput or productivity. Intuitively, the melting energy for metals is higher than that for plastics; metal casting shows a higher range of energy consumption than the injection-molding process.

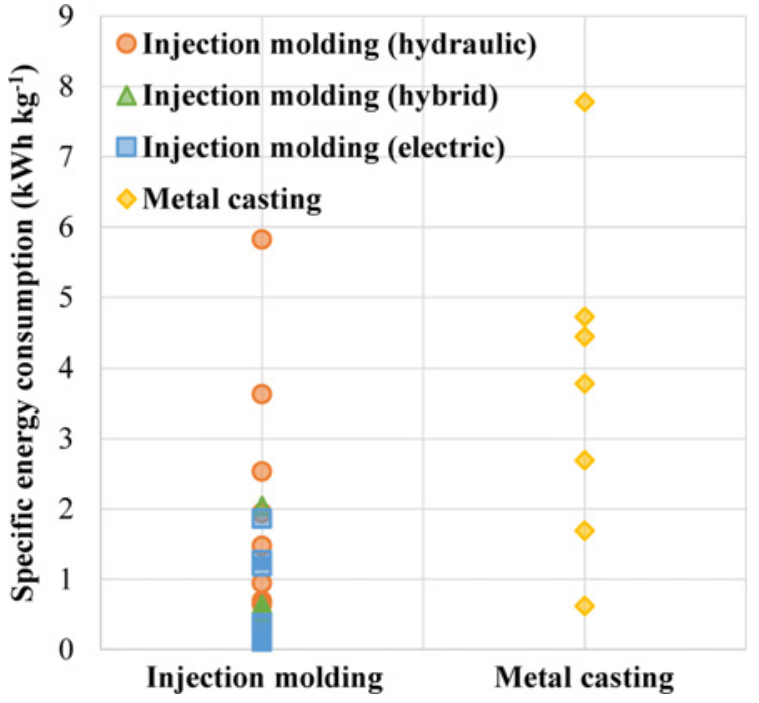

Fig. 8 SEC for conventional bulk-forming processes (constructed from Table 3)

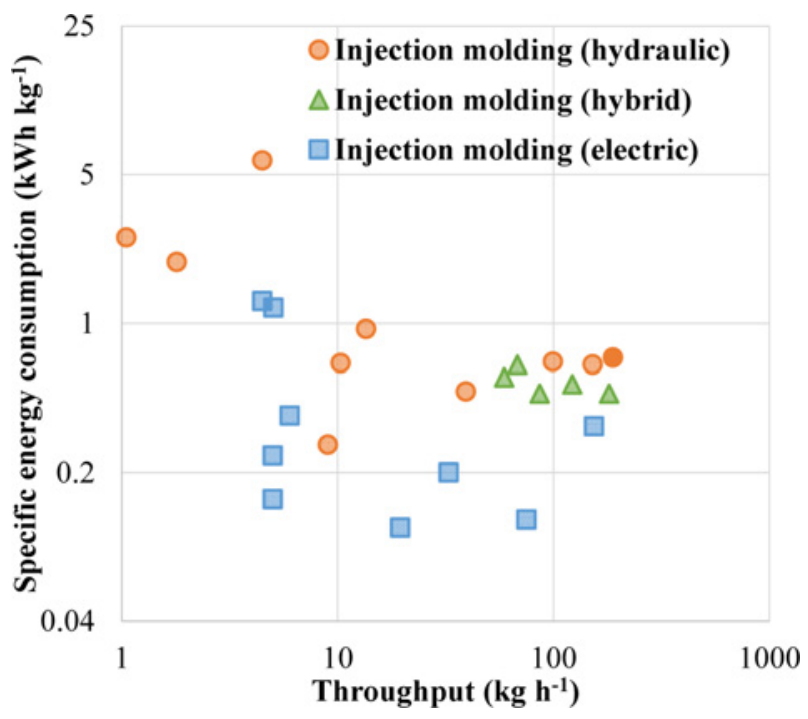

Fig. 9 SEC versus process productivity for various injection-molding processes (constructed from Table 3)

For injection molding, hydraulic machines consume slightly more energy than electric machines. Hydraulic power is the main power source for material injection; however, electric injection-molding machines are more efficient. In an SEAI report, the SEC of electrichydraulic hybrid molding machines is listed as $2.36 \mathrm{kWh} \mathrm{kg}^{-1}$, while that of a hydraulic machine is $2.91 \mathrm{kWh} \mathrm{kg}^{-1}{ }^{26}$ However, hydraulic machines offer advantages in terms of their injection rate and hold time, compared with electric-injection machines. ${ }^{38}$

Moreover, SEC shows a linear trend with respect to the reciprocal logarithmic form of the throughput rate, in good agreement with the literature; this was attributed to the constant power consumption of the process. $^{28,35}$ The range of throughputs for the hydraulic and electric machines was similar; however, the hydraulic cases consumed slightly more energy. These values will increase if additional activities are involved in the process. For example, the average value for the SEC in forging industries is $3.52 \mathrm{kWh} \mathrm{kg}^{-1}$, while that of metal-forming industries as a whole (including fasteners or sheet-metal forming) is $1.21 \mathrm{kWh} \mathrm{kg}^{-1} \cdot{ }^{45}$ 
Table 4 Classification of various machining (subtractive) processes ${ }^{48}$

\begin{tabular}{|c|c|c|}
\hline Category & Sub category & Processes \\
\hline \multirow{8}{*}{ Cutting } & \multirow{3}{*}{ Circular shapes } & Turning \\
\hline & & Boring \\
\hline & & Drilling \\
\hline & \multirow{5}{*}{ Various shapes } & Milling \\
\hline & & Planing \\
\hline & & Shaping \\
\hline & & Broaching \\
\hline & & Gear cutting \\
\hline \multirow{7}{*}{ Abrasion } & \multirow{3}{*}{ Bonded abrasives } & Grinding \\
\hline & & Honding \\
\hline & & Superfinishing \\
\hline & \multirow{4}{*}{ Loose abrasives } & Polishing \\
\hline & & Buffing \\
\hline & & Lapping \\
\hline & & Abrasive flow \\
\hline $\begin{array}{l}\text { Erosion } \\
\text { (Non- } \\
\text { traditional) }\end{array}$ & \multicolumn{2}{|c|}{$\begin{array}{c}\text { Chemical machining (CHM), } \\
\text { Electrochemical machining (ECM), } \\
\text { Electrical discharge machining (EDM), etc. }\end{array}$} \\
\hline
\end{tabular}

\subsection{Conventional Subtractive Processes}

Subtractive manufacturing processes remove a small amount of material from the bulk shape. Although material removal processes have been traditionally important, the concept 'subtractive' appeared following the development of the AM concept. In general, parts fabricated by conventional bulk-forming or AM processes require additional post-processing or finishing operations to obtain specific characteristics, such as dimensional accuracy or surface roughness. ${ }^{46}$

The concept of cutting or 'machining', a type of subtractive process, began in the 18th century. ${ }^{47}$ When James Watt built the first steam engine in 1776, he encountered significant difficulty in boring the cylinder. This problem was solved by John Wilkinson, who invented the horizontal-boring machine, the first effective cutting machine tool. Since this time, various types of machine tool have been developed. Table 4 shows the classification of various machining (i.e., subtractive) processes.

In the present study, conventional range-cutting processes were considered (e.g., milling, drilling, and grinding); traditional mechanical cutting processes were the main consideration, because these processes have been most widely adopted in industrial sectors for micro-scale ${ }^{49}$ and biomedical applications. ${ }^{50}$

To achieve the required dimensional accuracy and surface roughness for the product, conventional range-machining processes are generally essential; however, this process may have longer processing times, as well as significant material and electric-energy waste. To overcome these negative environmental aspects of machining, research has been conducted to evaluate the energy consumption of machine tools. The machine tool used for machining consists of various electricity-consuming components (e.g., the spindle, stage, coolant pump, numerical control (NC), and light). Fig. 10 provides a representation of the power distribution among the machine components. $^{51}$

Of them, basic consumption energy in the idle state, comprises a significant portion. Cutting energy varied according to the cutting condition, and might be lower than idle energy. From the perspective of consisting components, much research has focused on building an

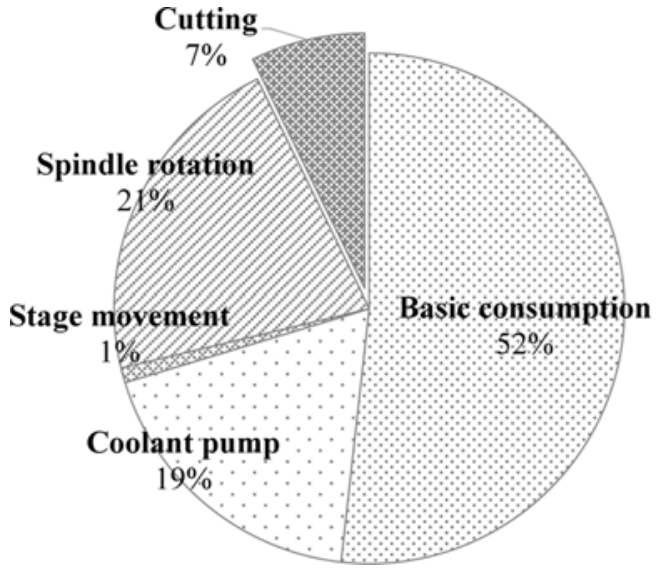

Fig. 10 Power distribution for the milling process (redrawn using data from Yoon et al. ${ }^{51}$ with permission from Elsevier)

energy model from component electricity consuming pattern. ${ }^{52}$

CO2PE! suggested a unified taxonomy/methodology to collect energy data in a more standardized format, globally compatible across various manufacturing processes. In the proposed system, the machinetool state is classified into two categories: the 'basic state' and the 'cutting state'. ${ }^{33}$ The basic-state energy includes the startup, computer units, lighting, cooling fans, lubrication, and unloaded motors. The cutting-state energy includes the cutting energy of the tool tip and the coolant energy.

Kellens et al. evaluated drilling using the screening approach proposed by CO2PE!. The total processing time was composed of the basic time (standby), idle time (partial mode), and drilling-mode time (full mode) $)^{53} \mathrm{Li}$ et al. separated the normal-cutting state and air-cutting state of the energy model. ${ }^{54}$ Similarly, Salonitis et al. created an energy model for machining by dividing the basic consumption and additional cutting load energy. ${ }^{55}$ The additional load energy can be represented as a function of the process parameters that affect the machining characteristics.

Mori et al. created an energy model for drilling and end/facemilling. ${ }^{56}$ The total power consumption value, $P_{\text {TOTAL }}(\mathrm{W})$, was expressed in terms of constant power consumption, cutting power consumption, and work/spindle positioning power consumption. He et al. estimated the electric energy consumption from NC code. Energy consumption was divided among the individual components, and an energy consumption model was constructed for each component, based on experiments. ${ }^{57}$ Mativenga et al. classified the machining process and electricity consumed in terms of the setup, cutting, tool change, and tool-producing energy. ${ }^{58}$

Guo et al. attempted to determine the optimum-cutting conditions to minimize energy consumption, for fine-surface quality with finish turning. ${ }^{59}$ To determine the optimal conditions, they constructed an energy model, based on component decomposition. In this case, the total specific energy (TSE) consisted of the specific process energy (SPE) and specific constant energy (SCE). SPE represents variable processing power, and SCE represents the constant power of the machine tools. According to the experimental results, TSE could not be quantified by the cutting parameters, due to the complexity of cutting processes. Instead, the TSE model was created by fitting the experimental values using empirical constants. As the cutting speed 
changed, the energy consumption varied as

$$
T S E=C_{0} \cdot v_{c}^{\alpha} \cdot f^{\beta} \cdot a_{p}^{\gamma} \cdot D^{\varphi}+\frac{C_{1}}{v_{c} \cdot f \cdot a_{p}}
$$

where $v_{c}$ is the cutting speed in $\mathrm{m} \mathrm{min}^{-1}, f$ is the feed rate in $\mathrm{mm} \mathrm{r}^{-1}$, $a_{p}$ is the depth of cut in $\mathrm{mm}, D$ is the final workpiece diameter in $\mathrm{mm}$, and $\alpha, \beta, \gamma$, and $\varphi$ are empirical constants. $C_{0}$ represents the machine power consumption constant, and $C_{1}$ represents the cutting power consumption constant.

Balogun et al. created an energy consumption model for turning and milling processes ${ }^{60}$ that included a 'ready state' between the 'basic state' and 'cutting state' of the CO2PE! model. The ready-state energy included the energy of the machine spindle, machine jog, pumps, servo home location, tool change, and swarf conveyors. This particular model predicted the consumption energy with $2-3 \%$ error, and modeled the cutting energy as a function of the material removal rate $\dot{m}\left(\mathrm{~mm}^{3} \mathrm{~s}^{-1}\right)$ and the specific cutting energy constant $k\left(\mathrm{~J} \mathrm{~mm}^{-3}\right)$ :

$$
E_{\text {TOTAL }}=\left(P_{0}+k \dot{m}\right) t
$$

where $P_{0}$ is the power consumed in the basic state, and $t$ is the processing time. SEC follows the reciprocal form of material removal value. Yoon et al. divided the energy consumption of the machine tool components into four elements: ${ }^{61}$

$$
E_{\text {TOTAL }}=E_{\text {BASIC }}+E_{\text {STAGE }}+E_{\text {SPINDLE }}+E_{\text {MACHINING }}
$$

where $E_{B A S I C}$ is the energy consumed in the idle state of the machine tool, $E_{S T A G E}$ and $E_{S P I N D L E}$ represent the energy consumed in moving the stage and spindle in the air-cutting state, respectively, and $E_{\text {MACHINING }}$ is the energy consumed in the additional cutting load.

As indicated in previous studies, the additional cutting load is affected by the friction between cutting tool edges and the work material. Yoon et al. developed an empirical model for the cutting energy, and revealed that wear also impacts cutting energy. Additionally, they emphasized that the increase in the cutting energy caused by wear is not proportional to the absolute amount of cutting energy, highlighting the need for an empirical model. ${ }^{51}$

For modeling the energy consumption of the cutting process, the material removal rate (MRR) is one of the indices used to reflect machining efficiency. Numerous studies have investigated the effect of MRR on SEC values. Table 5 lists the SEC of various machining processes.

Milling, turning, drilling, and grinding were handled with various materials and scales of tools. Kara and Li analyzed the relationship between SEC and MRR for various machine tools, ${ }^{22}$ the SECs were fitted in terms of the reciprocal logarithmic form of the MRR values with specific coefficients. This approach is consistent with other research (e.g., Diaz et al. ${ }^{62}$ and Li et al. ${ }^{54}$ ). Additionally, Neugebauer et al. analyzed selected targeted performances of various machine tools, and showed a spectrum of machining processes, based on several criteria. $^{66}$

Fig. 11 shows the SEC range in terms of the machining process. Milling exhibited a wide energy-consumption range; however, grinding

\begin{tabular}{|c|c|c|c|}
\hline Process & $\begin{array}{c}\text { Specific energy } \\
\text { consumption }\left(\mathrm{J} \mathrm{mm}^{-3}\right)\end{array}$ & Work material & Reference \\
\hline \multirow{8}{*}{ Milling } & $6.8^{*}$ & Mild steel & \multirow[b]{2}{*}{ Kara and $\mathrm{Li}^{22}$} \\
\hline & $14.5^{*}$ & $\begin{array}{l}\text { High tensile } \\
\text { steel }\end{array}$ & \\
\hline & $28.5^{*}$ & $\mathrm{~S} 45 \mathrm{C}$ & He et al. ${ }^{57}$ \\
\hline & $11.1-151.8$ & 1018 Steel & Diaz et al. ${ }^{62}$ \\
\hline & $30-188$ & $\mathrm{~S} 45 \mathrm{C}$ & Li et al. ${ }^{54}$ \\
\hline & $43.5-90.0^{*}$ & $\mathrm{Al} 6061$ & Pervaiz et al. ${ }^{63}$ \\
\hline & $2.3-4.9$ & Aluminum & \multirow{2}{*}{ Dahmus et al. ${ }^{64}$} \\
\hline & $10.0-60.0$ & Steel & \\
\hline \multirow{6}{*}{ Turning } & $9.8^{*}$ & Brass & \multirow{2}{*}{ Kara and $\mathrm{Li}^{22}$} \\
\hline & $7 *$ & Mild steel & \\
\hline & $2.7-9.8^{*}$ & Brass & \multirow{2}{*}{ Li et al. ${ }^{65}$} \\
\hline & $5.3-12.3^{*}$ & Mild steel & \\
\hline & $12.9-36.2 *$ & Steel (EN8) & $\begin{array}{l}\text { Mativenga and } \\
\text { Rajemi }^{58}\end{array}$ \\
\hline & $7.1-14.5$ & 42CrMo4 & Neugebauer et al. ${ }^{66}$ \\
\hline \multirow{2}{*}{ Drilling } & $65^{*}$ & Grey cast iron & He et al. ${ }^{57}$ \\
\hline & 9-38 & Grey cast iron & Neugebauer et al. ${ }^{66}$ \\
\hline Grinding & 343.4-1982.6 & & Li et al. ${ }^{67}$ \\
\hline
\end{tabular}
and drilling consumed slightly more energy for the removal of a
Table 5 SEC for various subtractive processes

* Calculated

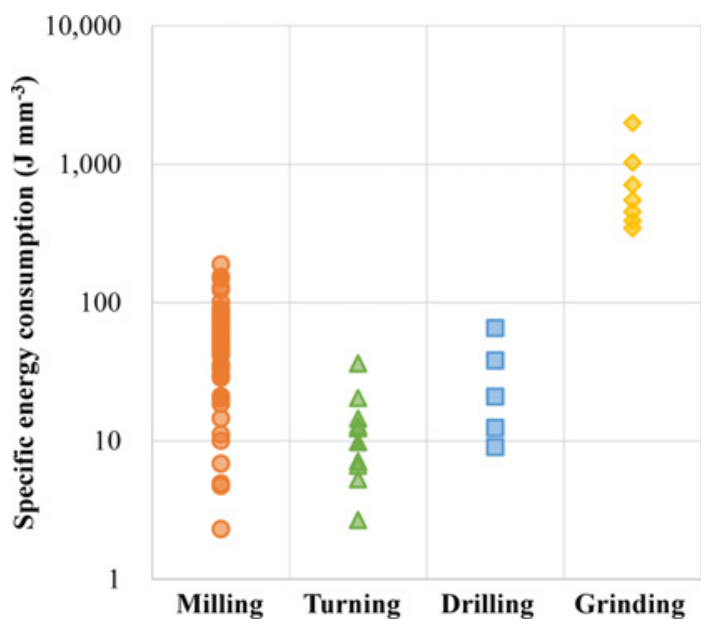

Fig. 11 SEC for conventional machining processes (constructed from Table 5)

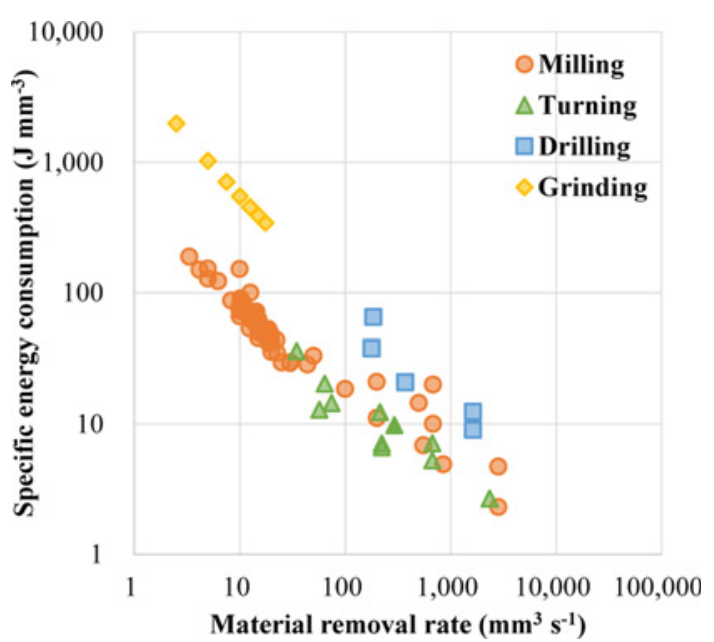

Fig. 12 SEC versus material removal rate for various conventional machining processes (constructed from Table 5) 
specific volume of material; the differences were attributed to the material removal value. Intuitively, SEC increases as the material removal decreases, due to the constant power consumption of the machine tools.

SEC is plotted in Fig. 12 in terms of the MRR for various machining processes. Although SEC varies over a certain range, the overall trend retains its linearity through the milling, turning, drilling, and grinding processes.

\subsection{Additive Processes}

AM processes, generally known as 3-D printing (3DP), basically form a structure using layer manufacturing (LM) technologies. The term 'three-dimensional printing' was first used in a Massachusetts Institute of Technology (MIT) patent, issued in $1993 .{ }^{68}$ The patent is one of several AM processes that use an inkjet-head system. However, the public quickly embraced the " $3-\mathrm{D}$ printing" terminology, as opposed to "AM" or "rapid prototyping" (RP). The first commercial 3D printer was invented by 3D Systems, Inc. in 1986. Charles W. Hull, the founder of 3D Systems, patented the apparatus and used it to produce 3-D structures with stereolithography technology. ${ }^{69}$ The concept of AM has itself been around for centuries; from this perspective, all conventional bulk-forming processes mentioned above can be included in the AM category.

In the present study, AM refers to a recently developed method used to form an object from a 3-D geometric model, based on LM technology. Because AM directly builds the part layer upon layer, it offers high flexibility in prototyping and manufacturing. ${ }^{70}$ For the production of a complex-shaped object with a limited number of runs, AM has a significant advantage in terms of the processing time and material usage, compared with conventional single and hybrid processes. Therefore, RP can be accomplished using several AM technologies, due to its geometric freedom and elimination of tooling. ${ }^{71}$ As such, the National Aeronautics and Space Administration (NASA) adopted a 3-D printer for the International Space Station for fabrication of alternative parts. ${ }^{72}$

AM has several drawbacks, in terms of its product quality, processing speed, and high cost. $^{73}$ From the perspective of energy consumption, AM processes are usually not as efficient as conventional manufacturing processes. For example, machine tools are equipped with many peripheral devices; thus, basic power consumption and processing time are two of the main considerations in energy consumption calculations. $^{73}$

AM processes involve the construction of a part that may consist of thousands of layers; thus, fabrication may require significantly more time than conventional manufacturing processes. Moreover, AM requires a significant amount of energy to form the thin layers from raw material, because the energy consumed per unit volume of the material is also high. Nevertheless, the remarkable advantages of AM, such as its flexibility, can contribute to improving the environmental aspects over the entire lifecycle of the product.

For example, using this technique, aerospace parts with complex geometries could adopt a more simple design with smaller geometric constraints, compared with injection molding $;{ }^{75}$ this would result in production of a part that is lighter in weight than a molded part. Additionally, the Advanced Manufacturing Office of the U.S.
Table 6 List of additive manufacturing methods ${ }^{74}$

\begin{tabular}{cc}
\hline \multirow{3}{*}{ Plastic methods } & Stereolithography apparatus (SLA) \\
\cline { 2 - 2 } & Selective Laser Sintering (SLS) \\
\cline { 2 - 2 } & Fused Deposition Modeling (FDM) \\
\hline & Three Dimensional Printing (3DP) \\
\cline { 2 - 2 } Direct Metal Laser Sintering (DMLS) \\
\cline { 2 - 2 } Selective Laser Melting (SLM) \\
\cline { 2 - 2 } & Electron Beam Melting (EBM) \\
\cline { 2 - 2 } & EasyCLAD \\
\cline { 2 - 2 } & Laser Consolidation (LC) \\
\hline
\end{tabular}

Department of Energy claims that AM saves energy by eliminating distributed manufacturing processes and material waste, ${ }^{77}$ citing remanufacturability with energy savings in engine production as an example. $^{39}$

Because it is very difficult to evaluate the environmental impact of AM processes, cradle-to-grave assessment may be required to analyze the benefits of this approach. ${ }^{76}$ In this review, the energy consumption model and sustainability of several AM processes were evaluated, and the experimental results were compared among processes and with respect to conventional manufacturing processes.

The AM process used for manufacturing a product depends on the material being machined. Table 6 shows a list of several AM methods. Among these various types, fused deposition modeling (FDM) and selective laser sintering (SLS) were considered in this review, due to the common use of these techniques in commercial 3-D printing. ${ }^{78}$

FDM extrudes molten material through a nozzle, and deposits it onto a substrate, using a moving stage. The molten material is extruded at room temperature, and then solidifies. The controllable scaffold used with FDM has allowed its application to tissue engineering, for example. ${ }^{79}$ The energy model for FDM is given as:

$$
E_{\text {TOTAL }}=E_{I N T}+E_{\text {HEATING }}+E_{S T A G E}
$$

where $E_{I N T}$ is the energy consumed in initial heating, $E_{\text {HEATING }}$ is the energy consumed in the heaters during the process, and $E_{\text {STAGE }}$ is the energy consumed in the moving stage.

In contrast, SLS uses metal powder and a laser to form layers by heating the powder. Powders are usually placed in a bed. The laser passes across a slice of the bed, corresponding to CAD model increments. As the laser passes across the powder slice, this part of the powder becomes sintered. This sintered area in the laser path becomes a slice or layer of the object being formed. After forming one layer, a roller moves across the powder surface to spread out unsintered powdered material. The process is then repeated. Various types of polymer, such as acrylonitrile butadiene styrene (ABS), polyester, and investment casting wax, as well as some metals and ceramic materials, have been used in this process. ${ }^{75}$

Verma and Rai investigated the energy consumption of the SLS process, and divided energy consumption into non-processing energy and laser processing energy. ${ }^{80}$ According to the authors, non-processing energy involves the energy consumed in roller movement, piston movement, and initial heating: 


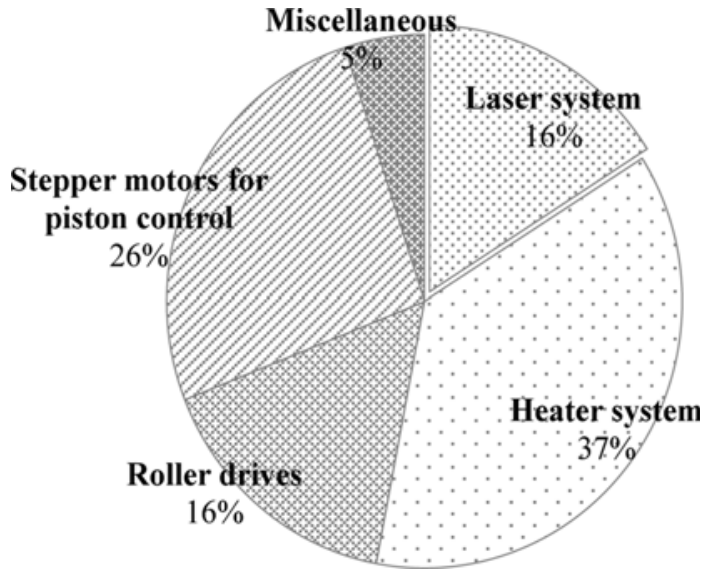

Fig. 13 Power diistribution of selective laser sintering (SLS) process (reproduced using data from Sreenicasan et al. ${ }^{81}$ )

$$
\begin{gathered}
E_{\text {TOTAL }}=E_{\text {PROCESSING }}+E_{\text {NON-PROCESSING }} \\
E_{\text {NON-PROCESSING }}=E_{I N I T}+E_{\text {ROLLER }}+E_{\text {STAGE }}
\end{gathered}
$$

where $E_{\text {PROCESSING }}$ is the energy consumed in laser processing, and $E_{N O N-}$ PROCESSING is the energy consumed in other devices, consisting of the energy consumed in initial heating $E_{I N I T}$, the energy consumed in roller movement $E_{R O L L E R}$, and the energy consumed in stage movement $E_{\text {SATGE }}$. They determined that laser processing accounted for $\sim 56 \%$ of the energy consumption. Sreenivasan et al. ${ }^{81}$ analyzed the power consumption of individual components in the SLS process. They determined that the laser system consumed $\sim 16 \%$ of the total energy (Fig. 13).

Table 7 lists the SEC of various AM processes. Junk and Côté directly compared the energy consumption of FDM and 3DP processes for production of a throttle valve. ${ }^{82}$ In this case, FDM consumed 180$230 \mathrm{~kJ}$ for production of a unit volume of material $\left(\mathrm{cm}^{3}\right)$, while 3DP consumed $55-65 \mathrm{~kJ} \mathrm{~cm}^{-3}$. The authors considered the entire energy consumption cycle, from the preparation step to the post-processing step. The most significant difference between the two processes was related to the temperature during fabrication. The FDM process required an operating temperature of $270^{\circ} \mathrm{C}$ for the nozzle; however, the $3 \mathrm{DP}$ process only required a temperature of $38^{\circ} \mathrm{C}$. Assuming the material is ABSplus made by Staratasys (density: $1.04 \mathrm{~g} \mathrm{~cm}^{-3}$ ), the SEC was converted to units of $\mathrm{kWh} \mathrm{kg}^{-1}$.

Baumers et al. investigated the SEC of several AM processes: ${ }^{83}$ SLS, FDM, electron-beam melting (EBM), and selective laser melting (SLM). A 'spider'-shaped standardized geometry was used as the test sample, to assess the effect of geometric complexity on energy consumption. They determined that the SEC decreased as the machine deposition productivity $\left(\mathrm{kg} \mathrm{h}^{-1}\right)$ decreased. Also, production of a single part consumed more energy than a full build with multiple parts simultaneously. In another study, Baumers et al. analyzed the energy consumption of SLM and EBM for processing stainless steel and titanium. ${ }^{84}$ According to their results, the energy consumptions per unit mass were 31 and $17 \mathrm{kWh} \mathrm{kg}^{-1}$ for the SLM and EBM processes, respectively.

Mognol et al. analyzed the energy and environmental aspects of thermojets, FDM, and SLS. ${ }^{85}$ In this case, the energy consumption of the AM processes above was determined with respect to part

\begin{tabular}{|c|c|c|c|}
\hline Process & \multicolumn{2}{|c|}{$\begin{array}{c}\text { Specific energy consumption } \\
\left(\mathrm{kWh} \mathrm{kg}^{-1}\right)\end{array}$} & Reference \\
\hline \multirow{6}{*}{ SLS } & \multicolumn{2}{|c|}{$29.83-40.09$} & Luo et al. ${ }^{86}$ \\
\hline & \multicolumn{2}{|c|}{36.04} & $\begin{array}{l}\text { Kellens et al. }{ }^{87} \\
\text { Baumers et al. }{ }^{83}\end{array}$ \\
\hline & \multicolumn{2}{|c|}{14.5} & Sreenivasan and Bourell ${ }^{88}$ \\
\hline & \multicolumn{2}{|c|}{29.72} & $\begin{array}{c}\text { Baumers et al. }^{83} \\
\left({ }^{*} \text { multiple parts }\right)\end{array}$ \\
\hline & \multicolumn{2}{|c|}{$56.75-66.02$} & Baumers et al. ${ }^{89}$ \\
\hline & \multicolumn{2}{|c|}{$26.3-39.8$} & Kellens et al..$^{90}$ \\
\hline \multirow{4}{*}{ FDM } & \multicolumn{2}{|c|}{$23.08-163.69$} & Lup et al 86 \\
\hline & \multicolumn{2}{|c|}{346.4} & \\
\hline & \multicolumn{2}{|c|}{148.89} & $\begin{array}{c}\text { Baumers et al. }{ }^{83} \\
(* \text { single part })\end{array}$ \\
\hline & \multicolumn{2}{|c|}{ 48.1-61.4 } & $\begin{array}{l}\text { Junk and Côté }{ }^{82} \\
(* \text { calculated })\end{array}$ \\
\hline \multirow{10}{*}{ Other processes } & SLA & $20.70-41.38$ & Luo et al. ${ }^{86}$ \\
\hline & $3 \mathrm{DP}$ & $14.7-17.4$ & $\begin{array}{l}\text { Junk and Côté } \\
(* \text { calculated })\end{array}$ \\
\hline & \multirow[b]{2}{*}{ DMLS } & 24.2 & Bourhis et al. ${ }^{91}$ \\
\hline & & 94.17 & $\begin{array}{l}\text { Baumers et al. }{ }^{83} \\
(* \text { single part })\end{array}$ \\
\hline & \multirow{4}{*}{ SLM } & 31 & Baumers et al. ${ }^{84}$ \\
\hline & & 27 & $\begin{array}{l}\text { Kellens et al. }{ }^{92} \\
\text { Baumers et al. }{ }^{83}\end{array}$ \\
\hline & & 163.33 & $\begin{array}{l}\text { Baumers et al } .^{83} \\
\left({ }^{*} \text { single part }\right)\end{array}$ \\
\hline & & 29.4 & $\begin{array}{l}\text { Baumers et al. }{ }^{83} \\
(* \text { single part })\end{array}$ \\
\hline & \multirow[b]{2}{*}{ EBM } & 17 & Baumers et al. $^{84}$ \\
\hline & & 49.17 & $\begin{array}{c}\text { Baumers et al. }{ }^{83} \\
(* \text { single part })\end{array}$ \\
\hline
\end{tabular}

Table 7 SEC for various additive manufacturing (AM) processes

orientation. Similar to the results from other studies, most of the energy consumption came from heating and laser operation in FDM and SLS, respectively.

They also suggested energy-saving strategies for each process, including minimizing the support volume for FDM and minimizing the part height for SLS for energy savings of up to $\sim 61$ and $43 \%$, respectively. Fig. 14 shows the SEC with respect to several AM processes. Fig. 15 shows the SEC in terms of the productivity.

SLS and SLA use a laser to sinter the material; however, FDM uses heaters. In some FDM processes, heaters are used to maintain the temperature of the entire chamber to create a stable environment. This, in turn, increases the SEC of the FDM process, with lower energy intensity compared to the laser. Moreover, similar to previous cases, the SEC showed a linear trend in terms of the reciprocal form of the productivity. However, unlike conventional manufacturing processes, SEC may increase as the productivity increases (e.g., some SLA processes); this effect is related to the solidification rate of the raw material. In some cases, the fabricated part has a higher density with higher energy consumption from a higher sintering rate.

Kruth et al. revealed that the SLS critical energy ranged from 4$26 \mathrm{~mJ} \mathrm{~cm}{ }^{-2} \cdot{ }^{78}$ In other research, the power density of the SLS process ranged from $7.22-9.5 \mathrm{~mJ} \mathrm{~cm}^{-2}$, while SLM consumed much more energy, 2.86-6.5 $\mathrm{J} \mathrm{cm}^{-2} .{ }^{93}$ From the perspective of laser power, these values are lower than those required for cutting, melting, or hardening. 


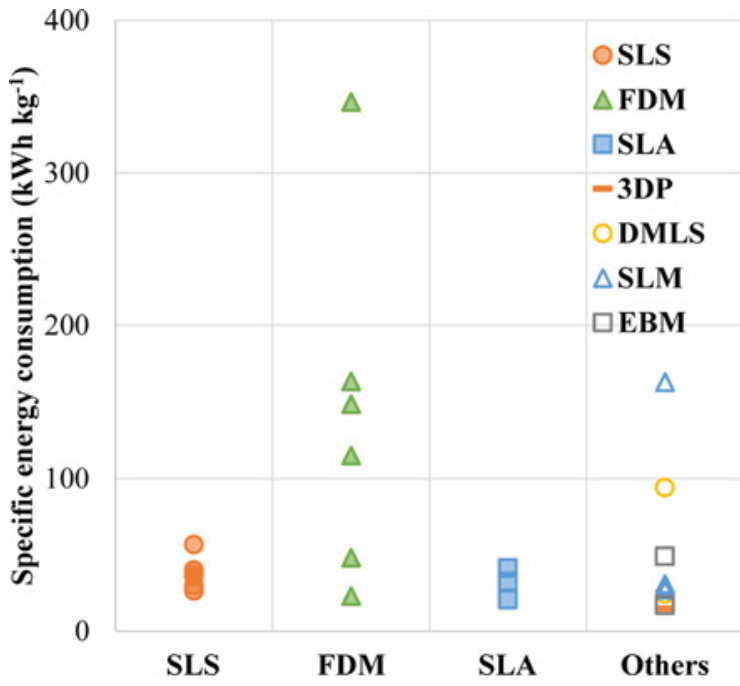

Fig. 14 Comparison of SEC for various additive manufacturing (AM) processes (constructed from Table 7)

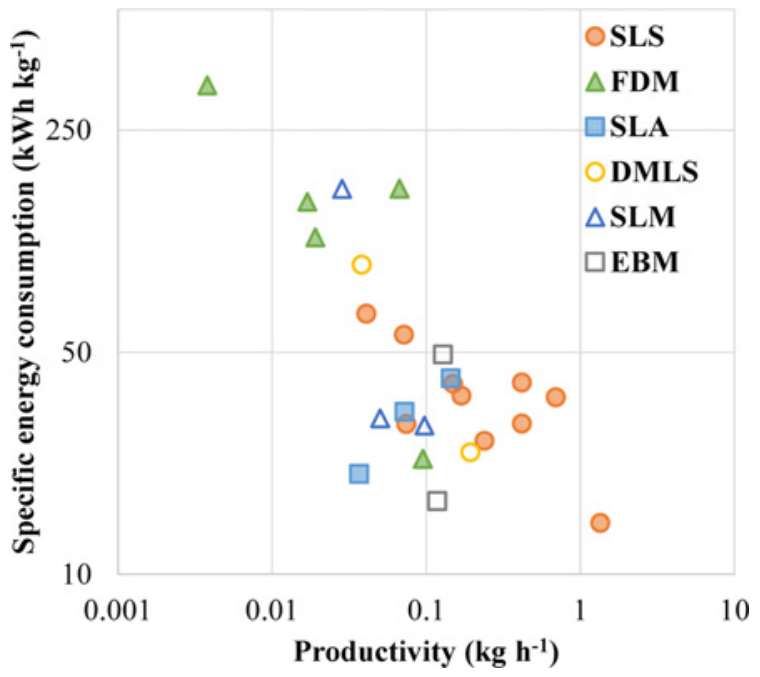

Fig. 15 SEC versus process productivity of various AM processes (constructed from Table 7)

However, due to the change in grain size, the energy density of the laser used in the SLS or SLM process affects the part density.

Several studies have performed a cost analysis of AM processes. Hopkinson and Dickens analyzed the production costs for SLA, FDM, and SLS, and compared the cost with that required for injection molding. ${ }^{71}$

In the Hopkins and Dickens research, machining, labor, and material costs were considered in the calculation, with the total cost per part given in Euros. For example, a labor part was 5.25 Euros for stereolithography, 4.47 Euros for FDM, and 2.20 Euros for SLS. Machine cost, material cost, and post-processing costs comprise a considerable portion of the overall cost of AM; thus, machine utilization should be optimized. ${ }^{94}$

Along with the many studies on AM processes, collaborative studies, such as project ATKINS, ${ }^{89}$ have attempted to address environmental concerns in rapid manufacturing processes. However, from the perspective of energy consumption reviewed here, AM offers an advantage for large build volumes, as well as a higher build rate for products having a small number of parts. ${ }^{95}$

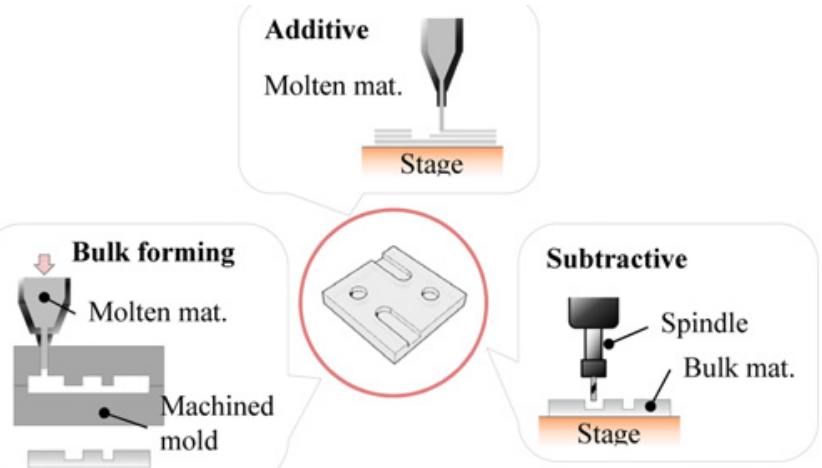

Fig. 16 Schematic diagram of the case study experimental set-up: fabrication of same test sample by conventional bulk-forming, subtractive, and additive processes

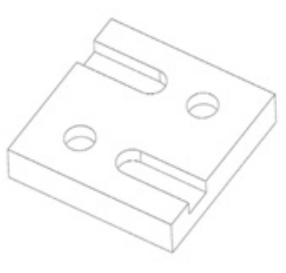

(a) CAD geometry

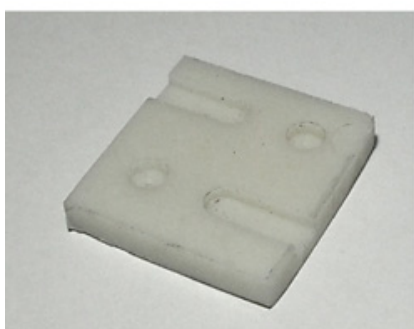

(c) Part fabricated by machining process

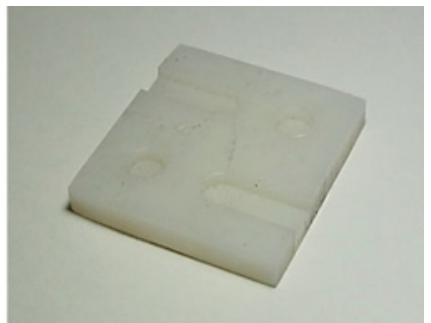

(b) Part fabricated by injectionmolding process

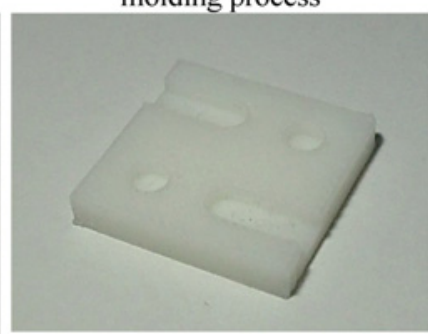

(d) Part fabricated by FDM process
Fig. 17 Test geometry for the experiments and fabricated results

\section{Case Study}

In addition to literature reviews, case studies were performed to compare experimentally determined energy-consumption values for bulk-forming, additive, and subtractive manufacturing processes. In the review of conventional bulk-forming processes, only the energy consumed in molding and casting was considered; the energy consumed in mold or core making was not included. Also, specific sample geometries were presented in the results from the literature.

In the case study experiments, energy consumption was measured for the three types of manufacturing process during the fabrication of a simple test part/model (Fig. 16). Fabrication and energy consumption were modeled with respect to individual machine states or components. To compare processes, a simple model for energy consumption measurement was designed, based on the feature design specified in the JSA guidelines; ${ }^{9}$ the scale of the model used was compatible with injection molding, milling, and FDM process fabrication. Fig. 17 shows the geometry of the standard sample used for comparison of energy consumption among the processes, and the fabricated results.

The size of the model was $30 \times 30 \times 5 \mathrm{~mm}$. The model had two holes 


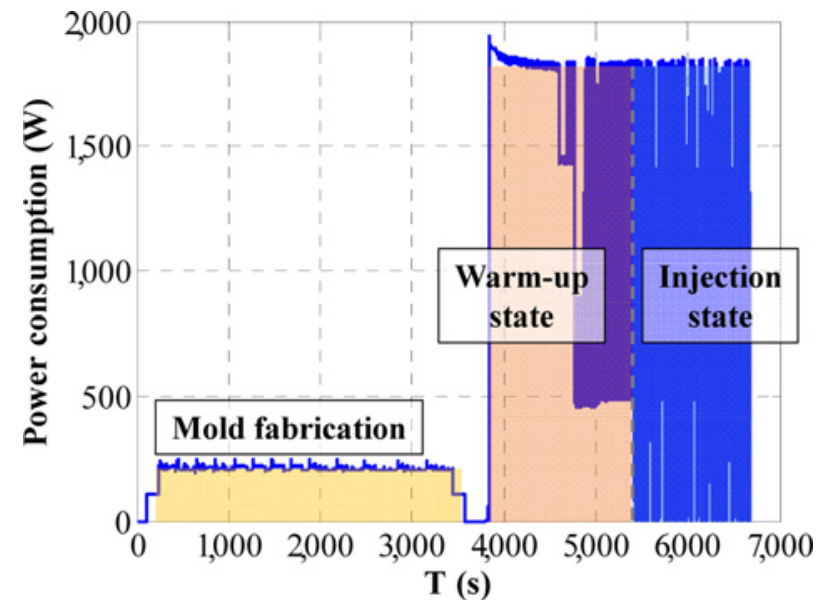

Fig. 18 Power profile for mold-making (milling) and the overall injection-molding process for fabrication of the test sample: the number of parts was five

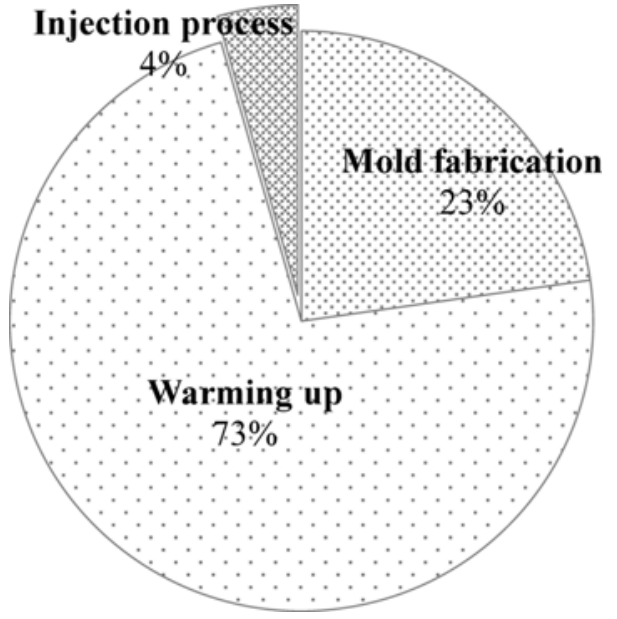

Fig. 19 Energy distribution of the injection-molding process: the number of parts was one

and slots, with a depth of $2 \mathrm{~mm}$. The scale of the model was determined by the working volume of the equipment. The workpiece material was ABS P400 (Stratasys Ltd., USA) (density: $1.05 \mathrm{~g} \mathrm{~cm}^{-3}$ ).

For each experiment, the electricity consumption of the machine was measured using a power meter (PAC3200, Siemens, Germany). The power meter was connected by an unshielded twisted pair (UTP) cable and Modbus protocol. The sampling rate of power consumption was $5 \mathrm{~Hz}$. The in-depth approach ${ }^{33,53}$ was used to calculate energy consumption, from the processing time and power measurements.

In the experiments, power consumption was measured and classified in terms of specific states and components, and then integrated for calculation.

\subsection{Injection Molding from Conventional Bulk-forming}

Before the injection-molding process, a mold was fabricated using a small CNC machine (NBS-3035, MNI Corp., Korea) and the countergeometry of the test sample. An end-mill tool (diameter: $5 \mathrm{~mm}$ ) (HAL1F, LK TOOL Corp., Korea) was used for machining (rotational speed: $18,000 \mathrm{rpm}$; feed rate: $200 \mathrm{~mm} \mathrm{~min}^{-1}$; and axial depth of cut: $0.5 \mathrm{~mm}$ ). The mold material was aluminum, $\mathrm{Al} 6061$. The top mold was

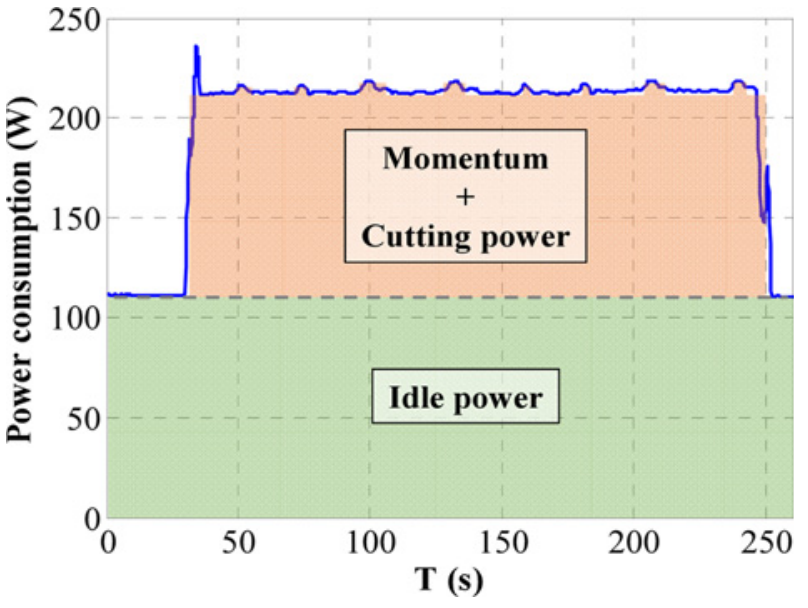

Fig. 20 Power profile of the milling (subtractive) process for fabrication of the test sample

$110 \times 110 \times 10 \mathrm{~mm}$, and the bottom mold was $110 \times 110 \times 20 \mathrm{~mm}$ in size. A small injection-molding machine (G-100T, Morgan Industries, Inc., USA), equipped with an electric heater and hydraulic injector, was used. Injection was available for up to $\sim 113 \mathrm{~g}$ of material; the maximum injection pressure was $\sim 82.7 \mathrm{MPa}$. During the process, the temperature of the material barrel and nozzle was maintained at $230^{\circ} \mathrm{C}$, and that of a plate under the mold was maintained at $120^{\circ} \mathrm{C}$. Fig. 18 shows the power profile for mold-making (milling) and the overall injection-molding process.

Because only the electricity was measured, energy consumed by the heaters was the main focus. Warm-up took $\sim 27 \mathrm{~min}$, after which the heaters were turned on and off to maintain the temperature. During the warm-up state, the heaters consumed $1339 \mathrm{~W}$; the average power consumption was $\sim 534 \mathrm{~W}$. The total processing time for cutting was $54.0 \mathrm{~min}$, and that of injection molding was $31.3 \mathrm{~min}$, including 27.1 minutes of warm-up. After warm-up, part fabrication took only $\sim 4.2 \mathrm{~min}$ or $\sim 250 \mathrm{~s}$. The part was designed to be slightly larger than the sample to form a fillet, and was then cut during the post-processing procedure.

The total energy consumption was $832.4 \mathrm{Wh}$, including $189.3 \mathrm{Wh}$ for mold fabrication and 606.1 Wh for warm-up. Fabrication of one standard sample required $832.4 \mathrm{Wh}$ per part, or $222.0 \mathrm{kWh} \mathrm{kg}^{-1}$.

However, the SEC decreased significantly as the number of parts to be fabricated increased, because the processing energy accounted for only $37.0 \mathrm{Wh}$ per part or $9.9 \mathrm{kWh} \mathrm{kg}^{-1}$. Fig. 19 shows the energy distribution of the overall process.

\subsection{Milling from a Conventional Subtractive Process}

For the subtractive process case study, a CNC machine (NBS-3035, MNI Corp., Korea) was used to fabricate the sample using an end-mill tool (diameter: $5 \mathrm{~mm}$ ) (HAL1F, LK TOOL Corp., Korea). The CNC machine had a working volume of $310 \times 360 \times 200 \mathrm{~mm}$. Because the model had two slots and two holes, machining included two slot millings and two drillings (rotational speed: 18,000 rpm; feed rate: $200 \mathrm{~mm} \mathrm{~min}^{-}$ ${ }^{1}$; and axial depth of cut: $1.0 \mathrm{~mm}$ ). Fig. 20 shows the power profile during cutting. Although $P_{\text {MACHINING }}$ was acquired from the cutting load, the cutting power was not large given the momentum energy; this was attributed to the material used, ABS P400, a relatively soft material.

During the machining process, $P_{I D L E}$ was $\sim 111.1 \mathrm{~W}, P_{\text {SPINDLE }}$ was $100.7 \mathrm{~W}$, and $P_{\text {STAGE }}$ was $8.0 \mathrm{~W}$. $P_{\text {MACHINING }}$ accounted for $\sim 6 \mathrm{~W}$ during 


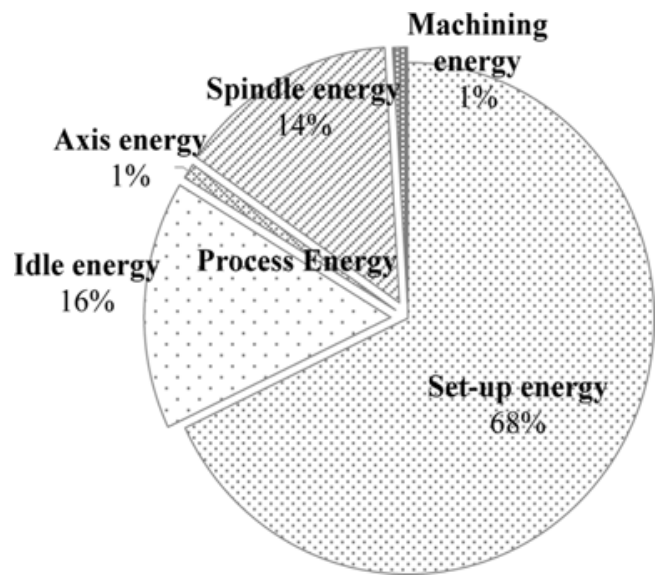

Fig. 21 Energy distribution of the overall milling process

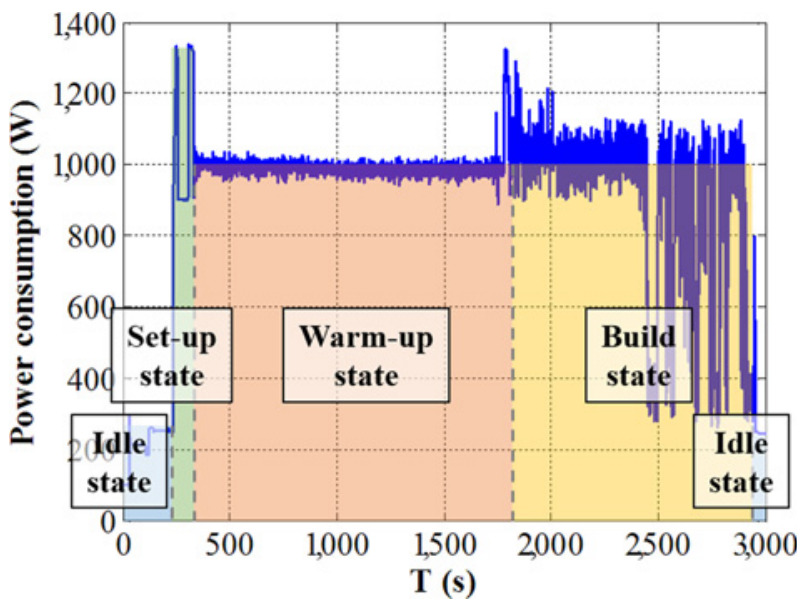

Fig. 22 Power profile of the FDM process for fabrication of the test sample

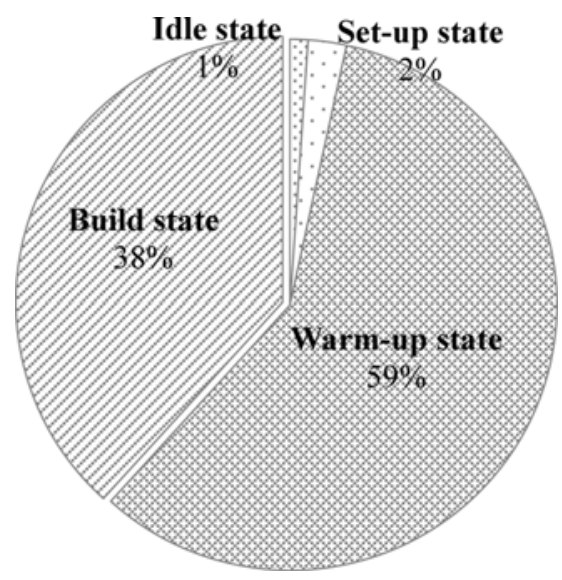

Fig. 23 Energy distribution of the overall FDM process: the number of parts was one

cutting, and varied with respect to the cutting load. The total processing time was $1123 \mathrm{~s}$, with 15.0 -min preparation time included. The total energy consumption was $40.8 \mathrm{Wh}$.

Fabrication of one standard sample required $40.8 \mathrm{Wh}$ per part, or $10.9 \mathrm{kWh} \mathrm{kg}^{-1}$ (remained mass). However, machining one part consumed only $3.49 \mathrm{kWh} \mathrm{kg}^{-1}$. Fig. 21 shows the energy distribution of the subtractive process.

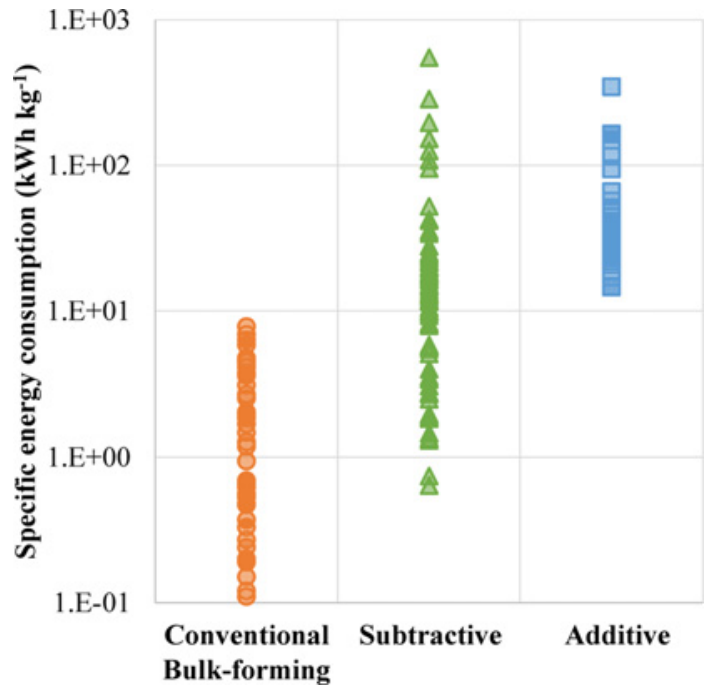

Fig. 24 SEC for the three categories of manufacturing process

\subsection{Fused Deposition Modeling from the Additive Process}

A small FDM machine (Dimension 768 SST, Stratasys Ltd., USA) was used to fabricate the sample. This machine has a working volume of $203 \times 203 \times 304 \mathrm{~mm}$. The thickness of one layer was $0.254 \mathrm{~mm}$.

During processing, the temperature was maintained at $230^{\circ} \mathrm{C}$ at the nozzle and $70^{\circ} \mathrm{C}$ in the chamber. The set-up (Idle + Set-up + Warm-up) took $31 \mathrm{~min}$. The total model build time was $18 \mathrm{~min}$. Fig. 22 shows the power profile of the FDM process.

From the idle state, the machine started to warm up the chamber and nozzle. Because the required temperature was significantly higher than room temperature, the warm-up process required $25 \mathrm{~min}$ before initiation of layer fabrication. When the warm-up period ended, the machine initiated material ejection. During the process, the heaters were turned on for $620 \mathrm{~s}$ (for the support material), and then turned on and off to maintain the required temperature (for material fabrication). The total energy consumption was $717.1 \mathrm{Wh}$. One standard sample required 717.1 Wh per part, or $191.3 \mathrm{kWh} \mathrm{kg}^{-1}$.

Because the warm-up process consumed $435.5 \mathrm{Wh}$, fabrication of one more part would consume $75.1 \mathrm{kWh} \mathrm{kg}^{-1}$. If multiple parts were fabricated after the warm-up period, then the SEC decreased. Fig. 23 shows the energy distribution of the overall FDM process.

\section{Discussion}

The energy consumption of the three categories of manufacturing process studied in this review; i.e., bulk-forming, subtractive, and additive processes were compared, based on published reports and the results obtained in our experimental case studies. Fig. 24 shows the range of SEC in terms of the categorized manufacturing processes, and Fig. 25 shows the trend of SEC in terms of process productivity. Conventional bulk-forming processes consume less energy than subtractive and additive processes, and additive processes have the highest range of SEC.

In this review, though the subtractive process did not include the energy consumed in forming a bulk material, SEC values for this process varied over a wide range. Gutowski et al. analyzed the material embodied energy in terms of exergy; ${ }^{96}$ however, the energy consumption of the machine tool 


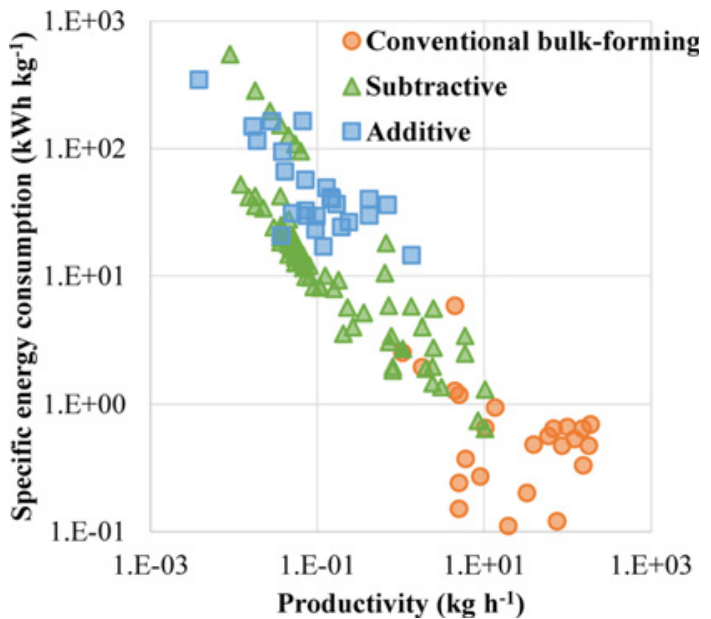

Fig. 25 SEC versus productivity for the three categories of manufacturing process

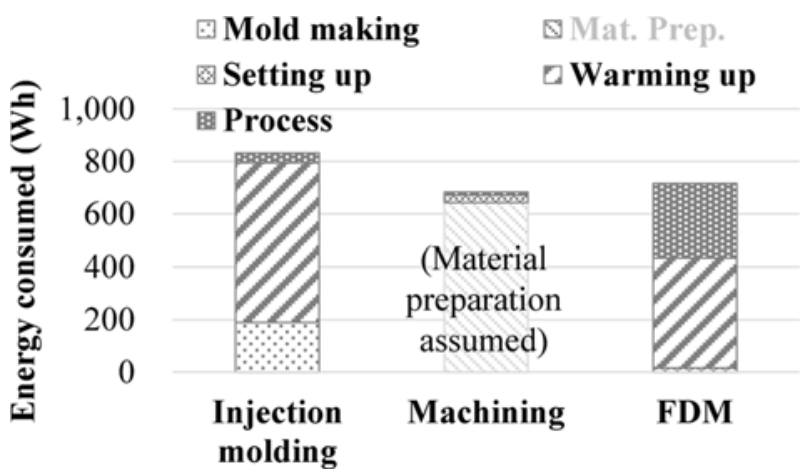

Fig. 26 Energy consumption results for the case studies: the number of products was one

itself varied significantly with the process scale and conditions. Conventional bulk-forming processes basically melted the material; however, the energy consumption for unit mass production could be reduced through mass production. The range of SEC values is displayed in Fig. 25. The SEC exhibited a linear trend with respect to the reciprocal logarithmic form of the productivity; these results were in good agreement with previous reports. ${ }^{36}$

In fact, conventional unit of productivity was different in terms of the type of processes. In subtractive processes, the cutting geometry and material have an impact on energy consumption. However, in bulkforming and subtractive processes, the density has an impact on energy consumption. For the integrated calculation, the work material was assumed to be a polymer (density: $\sim 1 \mathrm{~g} \mathrm{~cm}^{-3}$ or $1 \times 10^{-6} \mathrm{~kg} \mathrm{~mm}^{-3}$ ).

For the manufacturing processes shown in Fig. 25, conventional bulkforming exhibited the greatest productivity. From the graphs, AM processes may be considered to be the most inefficient, compared with conventional processes.

In addition to the literature review, case studies were also performed to show practical examples of energy consumption. In the case studies, the overall energy consumption of the entire process was measured, and divided into detailed elements and states using an in-depth approach.

Fig. 26 shows the energy consumed in the fabrication of the test sample using three different manufacturing processes. When the number of fabricated products was 1 , injection molding consumed the largest amount of energy, followed by FDM, and machining. Note that for the

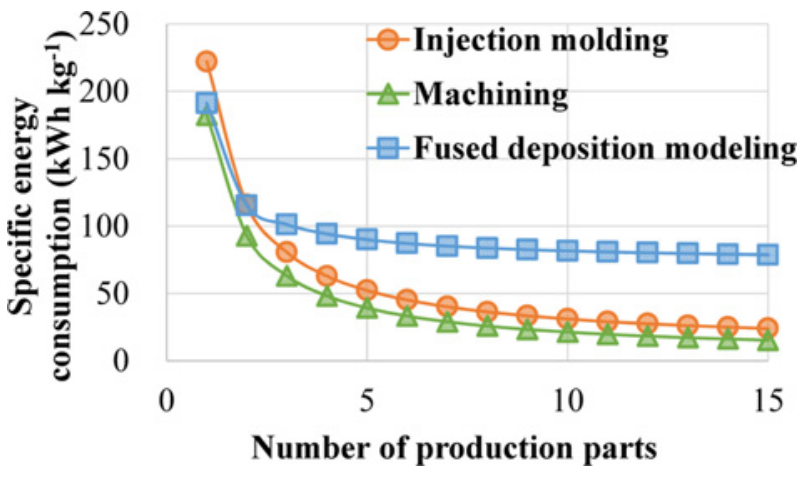

Fig. 27 SEC in terms of number of parts for injection molding, machining, and fused deposition modeling

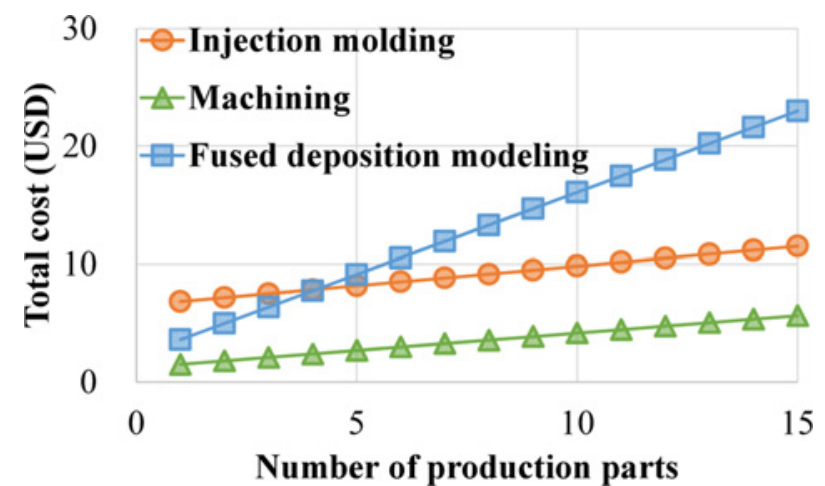

Fig. 28 Production costs in terms of number of parts for injection molding, machining, and fused deposition modeling

case study, we assumed that material formation for the machining process consumed the same amount of energy as the warming-up and process in injection molding.

Assuming that the bulk material was made by injection molding, the energy for bulk material fabrication should be similar to the energy consumption for the injection-molding process. Considering the energy consumed in mold making, AM may be more efficient than the injectionmolding process.

However, the energy distribution could vary in terms of the production number. The hatched area in Fig. 26 (referred to as "Process" in the legend) represents the pure process energy consumed in the fabrication of one part. Hence, that amount of energy will increase if the number of parts increases.

Although injection molding showed the highest energy consumption due to the considerable mold-making and warm-up energy required, the process energy was significantly lower than that required for the FDM process. Thus, FDM may be more efficient when the number of parts is one or two. In the case of multiple-parts fabrication, the working volume of the individual machine tool should be considered, because the set-up procedure is repeated for each manufacturing cycle.

Fig. 27 shows the SEC in terms of the number of production parts. Here, we assumed that set-up and material-preparation periods were needed only once for the production of 15 parts. As expected, the SEC was lower with FDM, when the number of parts was one. However, as the number of production parts increased, the SEC of injection molding and machining decreased significantly.

In contrast, Fig. 28 shows the total cost for production. Only energy 
and time costs were considered; material and machine costs were excluded. The energy cost was assumed to be 0.062 USD $(\mathrm{kWh})^{-1}$, which is the average price for electricity in South Korea. The time cost was assumed to be $4.75 \mathrm{USD} \mathrm{h}^{-1}$, which is the minimum wage in South Korea in 2014. Due to the time consumption involved in mold fabrication, the injection-molding cost was higher than FDM when the part number was less than three.

However when the number of parts exceeded three, the FDM cost increased sharply with wage cost. Although the detailed calculations may depend on local conditions, these energy and cost curves provide representative characteristics of the AM processes.

Therefore, both energy consumption and production cost should be carefully considered, in addition to the production size. In fact, additive processes have benefits other than product design. Mansour and Hague compared the manufacturing rules for injection molding and conventional rapid manufacturing. ${ }^{75}$ They determined that the general guidelines used for injection molding did not apply to AM processes, and that the part design could be simplified with specific features available with AM. For effective molding and ejection, the parts generally have geometric constraints; however, this is not a factor in AM. Moreover, a simplified part can contribute to the lightweight design of the part, and hence contribute to the overall efficiency of the product. For these reasons, the aerospace industry has tried to extend the application of AM techniques.

In addition, material preparation energy and cost needs to be carefully considered, for the wider range of assessment. In Fig. 26, material preparation energy for subtractive process was assumed to be same as in injection molding process; however material preparation consumes significant energy and time for most cases. Particularly for the AM processes, plastic materials are fabricated by special manufacturing processes, and can be expensive 53-104 times of materials for injection molding. ${ }^{77}$

The performances of each manufacturing process can also be estimated using various evaluation methods. For example, Peças et al. compared the effect of conventional molds and rapid-tooling molds, and suggested a global evaluation method based on the lifecycle assessment of the overall injection-molding process. ${ }^{97}$ Local conditions also have a marked effect on decision making, such as the cost of electricity or wage costs. However, modeling and assessment of the process should take precedence. For effective process planning, energy and environmental aspects should be modeled in terms of process and detail conditions.

\section{Conclusions}

Over the last several decades, sustainability has drawn much attention, particularly in manufacturing. In this review, an overview of energy consumption in manufacturing was provided for various manufacturing processes (bulk-forming, subtractive, and additive processes) to compare energy consumption. SEC estimates were collected for individual processing levels for the three manufacturing process types, and then categorized with respect to the manufacturing process and productivity. Emerging AM processes, spotlighted by the U.S. government, were considered, in addition to conventional manufacturing (bulk-forming and subtractive) techniques. We performed case studies for these three manufacturing processes and compared our SEC values with those obtained from the literature. The SEC of additive processes was $\sim 100$-fold higher than that of conventional bulk-forming processes. Subtractive processes generally had an intermediate value between the two categories, over a wide range from one to hundreds of $\mathrm{kWh} \mathrm{kg}^{-1}$. In the bulk-forming injectionmolding process, hydraulic molding machines consumed significantly higher energy than all electric-molding machines. Among the subtractive processes, grinding consumed the largest amount of energy compared with conventional milling techniques. In the case of AM processes, no significant difference between plastic and metal methods was evident.

All three process categories followed a linear trend with respect to the reciprocal form of the productivity. Similar to the SEC, the productivities associated with injection molding were $\sim 100$-fold higher than that of AM techniques. The MRR of subtractive processes also varied considerably, depending on the process scale.

In case studies, the energy consumption of each process was modeled in terms of individual components and states. Considering SEC, injection molding and machining were highly suitable techniques for fabrication. However, when the number of parts was small, FDM had a greater advantage, compared with conventional manufacturing processes.

Following the emerging demand for 'green' manufacturing, accurate assessment and modeling of manufacturing processes is becoming increasingly important. Data from various industrial fields can be used to effectively differentiate various manufacturing processes and facilitate decision-making regarding environmentally responsible manufacturing practices in industry.

\section{ACKNOWLEDGEMENT}

This work was supported by the Brain Korea 21 plus project, the National Research Foundation of Korea (NRF) grant funded by the Ministry of Education, Science and Technology (No. NRF-20100029227), and SNU-Hyundai NGV cooperative research projects funded by Hyundai WIA Corporation.

\section{REFERENCES}

1. U.S. Energy Information Administration, "International Energy Outlook 2013," http://www.eia.gov/forecasts/ieo/pdf/0484(2013).pdf (Accessed 17 February 2014)

2. Park, C. W., Kwon, K. S., Kim, W. B., Min, B. K., Park, S. J., et al., "Energy Consumption Reduction Technology in Manufacturing - A Selective Review of Policies, Standards, and Research," Int. J. Precis. Eng. Manuf., Vol. 10, No. 5, pp. 151-173, 2009.

3. Energy Information Administration, "Annual Energy Review 2011," Government Printing Office, http://www.eia.gov/totalenergy/data/ annual/\#consumption (Accessed 17 February 2014)

4. Ahn, S. H., "An Evaluation of Green Manufacturing Technologies 
based on Research Databases," Int. J. Precis. Eng. Manuf.-Green Tech., Vol. 1, No. 1, pp. 5-9, 2014.

5. CECIMO, “CECIMO Self-regulatory Initiative," http:// www.cecimo.eu/site/publications/magazine/cecimo-self-regulatoryinitiative/ (Accessed 17 February 2014)

6. European Commission, "Energy Efficiency Directive," Informal Energy Council, pp. 1-4, http://ec.europa.eu/energy/efficiency/eed/ doc/20120424_energy_council_non_paper_efficiency_en.pdf (Accessed 17 February 2014)

7. Fraunhofer-institut für Zuverlässigkeit und Mikrointegration (IZM) and Fraunhofer-institut für Produktionsanlagen und Konstruktionstechnik (IPK), "Eco Machine Tools," http://www.eco machinetools.eu/typo/ (Accessed 17 February 2014)

8. Kellens, K., Dewulf, W., Overcash, M., Hauschild, M., and Duflou, J., "Methodology for Systematic Analysis and Improvement of Manufacturing Unit Process Life - Cycle Inventory (UPLCI) $\mathrm{CO}_{2} \mathrm{PE}$ ! Initiative (Cooperative Effort on Process Emissions in Manufacturing). Part 1: Methodology Description," International Journal of Life Cycle Assess, Vol. 17, No. 1, pp. 69-78, 2012.

9. Japanese Standards Association, "JIS Standards," http:// www.webstore.jsa.or.jp/webstore/Top/indexEn.jsp?lang=en (Accessed 17 February 2014)

10. The International Organization for Standardization, "ISO Standards," http://www.iso.org/iso/home/standards.htm (Accessed 17 February 2014)

11. Jönsson, M., Andersson, C., and Ståhl, J. E., "A General Economic Model for Manufacturing Cost Simulation," in: Manufacturing Systems and Technologies for the New Frontier, Jönsson, M., Andersson, C., and Ståhl, J. E., (Eds.), Springer, pp. 33-38, 2008.

12. Innovation, M., "Obama Administration Launches Competition for Three New Manufacturing Innovation Institutes,” MRS Bulletin, Vol. 38, No. 10, pp. 776-777, 2013.

13. Obama, B. H., "Remarks by the President in State of the Union Address," The White House, http://www.revistalafactoria.eu/ articulos/VO\%20AMERICANA.pdf (Accessed 17 February 2014)

14. Advanced Manufacturing National Program Office, "National Network for Manufacturing Innovation (NNMI)," http:// www.manufacturing.gov/nnmi.html_(Accessed 17 February 2014)

15. Yeh, C. C., "Trend Analysis for the Market and Application Development of 3D Printing," International Journal of Automation and Smart Technology, Vol. 4, No. 1, pp. 1-3, 2014.

16. Atmel, "Analyst: 3D Printing Industry Set for Incredible Growth," http://atmelcorporation.wordpress.com/2013/09/18/analyst-3dprinting-industry-set-for-incredible-growth/ (Accessed 22 May 2014)

17. The White House, "President Obama Signs Executive Order Promoting Industrial Energy Efficiency," http://www.whitehou se.gov/the-press-office/2012/08/30/president-obama-signs-executive- order-promoting-industrial-energy-effici (Accessed 17 February 2014)

18. Vijayaraghavan, A. and Dornfeld, D., "Automated Energy Monitoring of Machine Tools," CIRP Annals-Manufacturing Technology, Vol. 59, No. 1, pp. 21-24, 2010.

19. Wang, Q., Liu, F., and Li, C., "An Integrated Method for Assessing the Energy Efficiency of Machining Workshop," Journal of Cleaner Production, Vol. 52, pp. 122-133, 2013.

20. Duflou, J. R., Sutherland, J. W., Dornfeld, D., Herrmann, C., Jeswiet, J., et al., "Towards Energy and Resource Efficient Manufacturing: A Processes and Systems Approach," CIRP AnnalsManufacturing Technology, Vol. 61, No. 2, pp. 587-609, 2012.

21. Lawrence Livermore National Laboratory, "Estimated U.S. Energy Use in 2012: 95.1 Quads," https://flowcharts.llnl.gov/content/ energy/energy_archive/energy_flow_2012/2012newUSEnergy.pdf (Accessed 17 February 2014)

22. Kara, S. and Li, W., "Unit Process Energy Consumption Models for Material Removal Processes," CIRP Annals-Manufacturing Technology, Vol. 60, No. 1, pp. 37-40, 2011.

23. Nancy, M., Keith, J., and Louise, D., "Energy and Environmental Profile of the U.S. Metalcasting Industry," U.S. Department of Energy, pp. 1-133, http://energy.gov/sites/prod/files/2013/11/f4/ profile_0.pdf (Accessed 17 March 2014)

24. Shifo, J. F. and Radia, J. T., "Theoretical/Best Proactive Energy Use in Metalcasting Operations," U.S. Department of Energy, pp. 1-116, http://energy.gov/eere/amo/downloads/itp-metal-castingtheoreticalbest-practice-energy-use-metalcasting-operations (Accessed 17 March 2014)

25. Banerjee, A. G., Li, X., Fowler, G., and Gupta, S. K., "Incorporating Manufacturability Considerations during Design of Injection Molded Multi-material Objects," Research in Engineering Design, Vol. 17, No. 4, pp. 207-231, 2007.

26. Sustainable Energy Authority of Ireland (SEAI), "Reduced Energy Consumption in Plastics Engineering," 2005 European Benchmarking Survey of Energy Consumption and Adoption of Best Practice, http://www.seai.ie/Your_Business/Large_Industry_En ergy_Network/Workshop_Presentations/Plastics_recipe.pdf (Accessed 17 March 2014)

27. Kordonowy, D. N., "A Power Assessment of Machining Tools," B.Sc. Thesis, Department of Mechanical Engineering, Massachusetts Institute of Technology, MA, USA, 2002.

28. Thiriez, A., "An Environmental Analysis of Injection Molding," M.Sc. Thesis, Department of Mechanical Engineering, Massac husetts Institute of Technology, 2006.

29. Mattis, J., Sheng, P., DiScipio, W., and Leong, K., "A Framework for Analyzing Energy Efficient Injection - Molding Die Design," Proc. of the IEEE International Symposium on Electronics and the Environment, pp. 207-212, 1996. 
30. Chien, J. M. and Dornfeld, D., "Semi-empirical Modeling of the Energy Consumed during the Injection Molding Process," in: Reengineering Manufacturing for Sustainability, Andrew, Y. C. N., Bin, S., and Soh-Khim, O., (Eds.), Springer, pp. 297-302, Springer, 2013.

31. Gantar, G., Glojek, A., Mori, M., Nardin, B., and Sekavčnik, M., "Resource Efficient Injection Moulding with Low Environmental Impacts," Strojniski Vestnik/Journal of Mechanical Engineering, Vol. 59, No. 3, pp. 193-200, 2013.

32. Chougule, R. G. and Ravi, B., "Casting Cost Estimation in an Integrated Product and Process Design Environment," International Journal of Computer Integrated Manufacturing, Vol. 19, No. 7, pp. 676-688, 2006.

33. Arasu, M. and Jeffrey, L. R., "Energy Consumption Studies in Cast Iron Foundries," Proc. of the $57^{\text {th }}$ Indian Foundry Congress, pp. 331336, 2009.

34. Duflou, J. R., Kellens, K., Guo, Y., and Dewulf, W., "Critical Comparison of Methods to Determine the Energy Input for Discrete Manufacturing Processes," CIRP Annals-Manufacturing Technology, Vol. 61, No. 1, pp. 63-66, 2012.

35. Thiriez, A. and Gutowski, T., "An Environmental Analysis of Injection Molding," Proc. of the IEEE International Symposium on Electronics and the Environment, pp. 195-200, 2006.

36. Gutowski, T., Dahmus, J., and Thiriez, A., "Electrical Energy Requirements for Manufacturing Processes," Proc. of the $13^{\text {th }}$ CIRP on Life Cycle Engineering, 2006.

37. Krishnan, S., Balasubramanian, N., Subrahmanian, E., Arun Kumar, V., Ramakrishna, G., et al., "Machine Level Energy Efficiency Analysis in Discrete Manufacturing for a Sustainable Energy Infrastructure," Proc. of the IEEE on Infrastructure Systems and Services: Developing 21st Century Infrastructure Networks, pp. 1-6, 2009.

38. Kanungo, A. and Swan, E., "All Electric Injection Molding Machines: How Much Energy Can You Save," Proc. of the $13^{\text {th }}$ Industrial Energy Technology Conference, Paper No. ESL-IE-08-0506, pp. 1-12, 2008.

39. Sutherland, J. W., Adler, D. P., Haapala, K. R., and Kumar, V., “A Comparison of Manufacturing and Remanufacturing Energy Intensities with Application to Diesel Engine Production," CIRP Annals-Manufacturing Technology, Vol. 57, No. 1, pp. 5-8, 2008.

40. Boustead, I. and Hancock, G., "Handbook of Industrial Energy Analysis," Ellis Horwood Limited, 1979.

41. Jones, A. J., "The Industrial Ecology of the Iron Casting Industry," M.Sc. Thesis, Department of Mechanical Engineering, Massachusetts Institute of Technology, MA, USA, 2007.

42. Dalquist, S. and Gutowski, T., "Life Cycle Analysis of Conventional Manufacturing Techniques: Die Casting," Massachusetts Institute of Technology, Paper No. LMP-MIT-TGG-03-12-09-2004, http:// web.mit.edu/ebm/www/Publications/Die\%20Casting\%20Dalquist\% 20Gutowski.pdf (Accessed 8 June 2014)
43. Hasanbeigi, A., Price, L., Chunxia, Z., Aden, N., Xiuping, L., et al., "A Comparison of Iron and Steel Production Energy Use and Energy Intensity in China and the U.S.," Ernest Orlando Lawrence Berkeley National Laboratory, pp. 1-77, http://china.lbl.gov/sites/all/ files/lbl-4836e-us-china-steeljune-2011.pdf (Accessed 17 March 2014)

44. Hasanbeigi, A., Price, L., Chunxia, Z., Aden, N., Xiuping, L., et al., "Comparison of Iron and Steel Production Energy Use and Energy Intensity in China and the U.S.," Journal of Cleaner Production, Vol. 65, pp. 108-119, 2014.

45. Carbon Trust, "Industrial Energy Efficiency Accelerator - Guide to the Metalforming Sector," https://www.carbontrust.com/media/206 500/ctg062-metalforming-industrial-energy-efficiency.pdf (Accessed 8 June 2014)

46. Schmid, K., "Manufacturing Processes for Engineering Materials," Prentice Hall, $5^{\text {th }}$ Ed., pp. 416-426, 2007.

47. Boothroyd, G., "Fundamentals of Metal Machining and Machine Tools," CRC Press, $3^{\text {rd }}$ Ed., pp. 1-2, 1988.

48. El-Hofy, H. A. G., "Fundamentals of Machining Processes: Conventional and Nonconventional Processes," CRC press, $2^{\text {nd }} E d$., Paper No. 4, 2013.

49. Yoon, H. S., Wu, R., Lee, T. M., and Ahn, S. H., "Geometric Optimization of Micro Drills using Taguchi Methods and Response Surface Methodology," Int. J. Precis. Eng. Manuf., Vol. 12, No. 5, pp. 871-875, 2011.

50. Kim, M. H., Kim, H. J., Kim, N. N., Yoon, H. S., and Ahn, S. H., "A Rotational Ablation Tool for Calcified Atherosclerotic Plaque Removal,” Biomedical Microdevices, Vol. 13, No. 6, pp. 963-971, 2011.

51. Yoon, H. S., Lee, J. Y., Kim, M. S., and Ahn, S. H., "Empirical Power-consumption Model for Material Removal in Three-axis Milling," Journal of Cleaner Production, http://dx.doi.org/10.1016/ j.jclepro.2014.03.061 (Accessed 8 June 2014)

52. Tampus, V., "Energy-saving Tactics for Machine Tools," Manufacturing Engineering, Vol. 150, No. 3, pp. 144-144, 2013.

53. Kellens, K., Dewulf, W., Overcash, M., Hauschild, M. Z., and Duflou, J. R., "Methodology for Systematic Analysis and Improvement of Manufacturing Unit Process Life Cycle Inventory (UPLCI) CO2PE! Initiative (Cooperative Effort on Process Emissions in Manufacturing). Part 2: Case Studies," International Journal of Life Cycle Assess, Vol. 17, No. 2, pp. 242-251, 2012.

54. Li, L., Yan, J., and Xing, Z., "Energy Requirements Evaluation of Milling Machines based on Thermal Equilibrium and Empirical Modelling," Journal of Cleaner Production, Vol. 52, pp. 113-121, 2013.

55. Salonitis, K. and Ball, P., "Energy Efficient Manufacturing from Machine Tools to Manufacturing Systems," Procedia CIRP, Vol. 7, pp. 634-639, 2013. 
56. Mori, M., Fujishima, M., Inamasu, Y., and Oda, Y., "A Study on Energy Efficiency Improvement for Machine Tools," CIRP AnnalsManufacturing Technology, Vol. 60, No. 1, pp. 145-148, 2011.

57. He, Y., Liu, F., Wu, T., Zhong, F., and Peng, B., "Analysis and Estimation of Energy Consumption for Numerical Control Machining," Proc. of the Institution of Mechanical Engineers, Part B: Journal of Engineering Manufacture, Vol. 226, No. 2, pp. 255$266,2012$.

58. Mativenga, P. and Rajemi, M., "Calculation of Optimum Cutting Parameters based on Minimum Energy Footprint," CIRP AnnalsManufacturing Technology, Vol. 60, No. 1, pp. 149-152, 2011.

59. Guo, Y., Loenders, J., Duflou, J., and Lauwers, B., "Optimization of Energy Consumption and Surface Quality in Finish Turning," Procedia CIRP, Vol. 1, pp. 512-517, 2012.

60. Balogun, V. A. and Mativenga, P. T., "Modelling of Direct Energy Requirements in Mechanical Machining Processes," Journal of Cleaner Production, Vol. 41, pp. 179-186, 2013.

61. Yoon, H. S., Moon, J. S., Pham, M. Q., Lee, G. B., and Ahn, S. H., "Control of Machining Parameters for Energy and Cost Savings in Micro-scale Drilling of PCBs," Journal of Cleaner Production, Vol. 54, pp. 41-48, 2013.

62. Diaz, N., Redelsheimer, E., and Dornfeld, D., "Energy Consumption Characterization and Reduction Strategies for Milling Machine Tool Use," in: Glocalized Solutions for Sustainability in Manufacturing, Hesselbach, J. and Herrmann, C., (Ed.), Springer, pp. 263-267, 2011.

63. Pervaiz, S., Deiab, I., Rashid, A., and Nicolescu, M., "An Experimental Analysis of Energy Consumption in Milling Strategies," Proc. of the IEEE on Computer Systems and Industrial Informatics, pp. 1-6, 2012.

64. Dahmus, J. B. and Gutowski, T. G., "An Environmental Analysis of Machining," Proc. of the ASME International Mechanical Engineering Congress and Exposition, pp. 643-652, 2004.

65. Li, W. and Kara, S., "An Empirical Model for Predicting Energy Consumption of Manufacturing Processes: A Case of Turning Process," Proc. of the Institution of Mechanical Engineers, Part B: Journal of Engineering Manufacture, Vol. 225, No. 9, pp. 16361646, 2011.

66. Neugebauer, R., Schubert, A., Reichmann, B., and Dix, M., "Influence Exerted by Tool Properties on the Energy Efficiency during Drilling and Turning Operations," CIRP Journal of Manufacturing Science and Technology, Vol. 4, No. 2, pp. 161-169, 2011.

67. Li, W., Winter, M., Kara, S., and Herrmann, C., "Eco-efficiency of Manufacturing Processes: A Grinding Case," CIRP AnnalsManufacturing Technology, Vol. 61, No. 1, pp. 59-62, 2012.

68. Sachs, E. M., Haggerty, J. S., Clima, M. J., and Williams, P. A., "Three-dimensional Printing Techniques," US Patent, No. US 5204055 A, 1993.
69. Hull, C. W., "Apparatus for Production of Three-dimensional Objects by Stereolithography," US Patent, No. US 4575330 A, 1986.

70. Dimitrov, D., Schreve, K., and De Beer, N., "Advances in Three Dimensional Printing-State of the Art and Future Perspectives," Journal for New Generation Sciences, Vol. 4, No. 1, pp. p. 21-49, 2006.

71. Hopkinson, N. and Dicknes, P., "Analysis of Rapid Manufacturing Using Layer Manufacturing Processes for Production," Proc. of the Institution of Mechanical Engineers, Part C: Journal of Mechanical Engineering Science, Vol. 217, No. 1, pp. 31-39, 2003.

72. Watson, K., Petersen, D., and Crockett, R., "Application of Solid Freeform Fabrication Technology to NASA Exploration Missions," Proc. of the Solid Freeform Fabrication Symposium, pp. 857-864, 1999.

73. Drizo, A. and Pegna, J., "Environmental Impacts of Rapid Prototyping: An Overview of Research to Date," Rapid Prototyping Journal, Vol. 12, No. 2, pp. 64-71, 2006.

74. Aliakbari, M., "Additive Manufacturing: State-of-the-art, Capabilities, and Sample Applications with Cost Analysis," M.Sc. Thesis, School of Industrial Engineering and Management, KTH, 2012.

75. Mansour, S. and Hague, R., "Impact of Rapid Manufacturing on Design for Manufacture for Injection Moulding," Proc. of the Institution of Mechanical Engineers, Part B: Journal of Engineering Manufacture, Vol. 217, No. 4, pp. 453-461, 2003.

76. U.S. Department of Energy, "Additive Manufacturing: Pursuing the Promise," https://www1.eere.energy.gov/manufacturing/pdfs/additive_ manufacturing.pdf (Accessed 17 February 2014)

77. Wohlers, T. and Caffrey, P. T., "Additive Manufacturing: Going Mainstream," Manufacturing Engineering, Vol. 150, No. 6, pp. 6773, 2013.

78. Kruth, J. P., Leu, M., and Nakagawa, T., "Progress in Additive Manufacturing and Rapid Prototyping," CIRP AnnalsManufacturing Technology, Vol. 47, No. 2, pp. 525-540, 1998.

79. Zein, I., Hutmacher, D. W., Tan, K. C., and Teoh, S. H., "Fused Deposition Modeling of Novel Scaffold Architectures for Tissue Engineering Applications," Biomaterials, Vol. 23, No. 4, pp. 1169$1185,2002$.

80. Verma, A. and Rai, R., "Energy Efficient Modeling and Optimization of Additive Manufacturing Processes," Proc. of the Solid Freeform Fabrication Symposium, pp. 231-241, 2013.

81. Sreenivasan, R., Goel, A., and Bourell, D., "Sustainability Issues in Laser-based Additive Manufacturing," Physics Procedia, Vol. 5, Part A, pp. 81-90, 2010.

82. Junk, S. and Côté, S., "A Practical Approach to Comparing Energy Effectiveness of Rapid Prototyping Technologies," Proc. of AEPR'12, 17 $7^{\text {th }}$ European Forum on Rapid Prototyping and Manufacturing, pp. 1-8, 2012. 
83. Baumers, M., Tuck, C., Wildman, R., Ashcroft, I., and Hague, R., "Energy Inputs to Additive Manufacturing: Does Capacity Utilization Matter?” EOS, Vol. 1000, No. 270, pp. 30-40, 2011.

84. Baumers, M., Tuck, C., Hague, R., Ashcroft, I., and Wildman, R., "A Comparative Study of Metallic Additive Manufacturing Power Consumption," Proc. of the Solid Freeform Fabrication Symposium, pp. 278-288, 2010.

85. Mognol, P., Lepicart, D., and Perry, N., "Rapid Prototyping: Energy and Environment in the Spotlight," Rapid Prototyping Journal, Vol. 12, No. 1, pp. 26-34, 2006.

86. Luo, Y., Ji, Z., Leu, M. C., and Caudill, R., "Environmental Performance Analysis of Solid Freedom Fabrication Processes," Proc. of the IEEE International Symposium on Electronics and the Environment, Paper No. 96, pp. 1-6, 1999.

87. Kellens, K., Dewulf, W., Deprez, W., Yasa, E., and Duflou, J., "Environmental Analysis of SLM and SLS Manufacturing Processes," Proc. of the CIRP International Conference on Life Cycle Engineering, pp. 423-428, 2010.

88. Sreenivasan, R. and Bourell, D., "Sustainability Study in Selective Laser Sintering - An Energy Perspective," Proc. of the Solid Freeform Fabrication Symposium, pp. 257-265, 2009.

89. Baumers, M., Tuck, C., Bourell, D., Sreenivasan, R., and Hague, R., "Sustainability of Additive Manufacturing: Measuring the Energy Consumption of the Laser Sintering Process," Proc. of the Institution of Mechanical Engineers, Part B: Journal of Engineering Manufacture, Vol. 225, No. 12, pp. 2228-2239, 2011.

90. Kellens, K., Yasa, E., Renaldi, R., Dewulf, W., Kruth, J. P., et al., "Energy and Resource Efficiency of SLS/SLM Processes," Proc. of the Solid Freeform Fabrication Symposium, Paper No. 79, pp. 1-16, 2011.

91. Le Bourhis, F., Kerbrat, O., Hascoet, J. Y., and Mognol, P., "Sustainable Manufacturing: Evaluation and Modeling of Environmental Impacts in Additive Manufacturing," International Journal of Advanced Manufacturing Technology, Vol. 69, No. 9-12, pp. 1927-1939, 2013.

92. Kellens, K., Yasa, E., Dewulf, W., and Duflou, J., "Environmental Assessment of Selective Laser Melting and Selective Laser Sintering," Going Green - Care Innovation: From Legal Compliance to Energy-efficient Products and Services, Paper No. 2.14.5, 2010.

93. Levy, G. N., "The Role and Future of the Laser Technology in the Additive Manufacturing Environment," Physics Procedia, Vol. 5, Part. A, pp. 65-80, 2010.

94. Lindemann, C., Jahnke, U., Moi, M., and Koch, R., “Analyzing Product Lifecycle Costs for a Better Understanding of Cost Drivers in Additive Manufacturing," Proc. of the Solid Freeform Fabrication Symposium, pp. 177-188, 2012.

95. Lindemann, C., Jahnke, U., Moi, M., and Koch, R., "Impact and Influence Factors of Additive Manufacturing on Product Lifecycle Costs," Proc. of the Solid Freeform Fabrication Symposium, pp. 998-1009, 2013.
96. Gutowski, T. G., Branham, M. S., Dahmus, J. B., Jones, A. J., Thiriez, A., et al., "Thermodynamic Analysis of Resources used in Manufacturing Processes," Environmental Science \& Technology, Vol. 43, No. 5, pp. 1584-1590, 2009.

97. Peças, P., Ribeiro, I., Folgado, R., and Henriques, E., “A Life Cycle Engineering Model for Technology Selection: A Case Study on Plastic Injection Moulds for Low Production Volumes," Journal of Cleaner Production, Vol. 17, No. 9, pp. 846-856, 2009. 